\title{
Organ Preservation into the 2020s: The Era of Dynamic Intervention
}

\author{
Alexander Petrenko $^{a}$ Matias Carnevale ${ }^{b, c} \quad$ Alexander Somov $^{a}$ Juliana Osorio $^{b}$ \\ Joaquin Rodríguez $^{\mathrm{b}}$ Edgardo Guibert ${ }^{\mathrm{b}, \mathrm{c}}$ Barry Fuller ${ }^{\mathrm{d}}$ Farid Froghi $^{\mathrm{d}}$ \\ ${ }^{a}$ Department of Cryobiochemistry, Institute for Problems of Cryobiology and Cryomedicine, Ukraine Academy \\ of Sciences, Kharkov, Ukraine; ${ }^{b}$ Centro Binacional (Argentina-Italia) de Investigaciones en Criobiología Clínica \\ y Aplicada (CAIC), Universidad Nacional de Rosario, Rosario, Argentina; ${ }^{C}$ Consejo Nacional de Investigaciones \\ Científicas y Técnicas (CONICET), Buenos Aires, Argentina; dUCL Division of Surgery and Interventional Sciences, \\ Royal Free Hospital, London, UK
}

\section{Keywords}

Organ preservation - Organ preservation solutions . Transplantation

\begin{abstract}
Organ preservation has been of major importance ever since transplantation developed into a global clinical activity. The relatively simple procedures were developed on a basic comprehension of low-temperature biology as related to organs outside the body. In the past decade, there has been a significant increase in knowledge of the sequelae of effects in preserved organs, and how dynamic intervention by perfusion can be used to mitigate injury and improve the quality of the donated organs. The present review focuses on (1) new information about the cell and molecular events impacting on ischemia/reperfusion injury during organ preservation, (2) strategies which use varied compositions and additives in organ preservation solutions to deal with these, (3) clear definitions of the developing protocols for dynamic organ perfusion preservation, (4) information on how the choice of perfusion solutions can impact on desired attributes of dynamic organ perfusion, and (5) summary and future horizons.

(c) 2019 S. Karger AG, Basel
\end{abstract}

\section{Introduction}

Organ transplantation has developed over the past 60 years from what could be considered a surgical research technique available to only a handful of patients into a globally accepted treatment for end organ failure [1-3]. Many advances have been made in the clinical understanding of the essential elements for success, including patient management, specialized surgical intervention, immunosuppression, and, of note in this review, organ preservation, which has been considered to be the supply line for clinical transplantation $[4,5]$. In this review we will consider (1) the history and current applications of organ preservation, (2) new achievements in our understanding of the ischemic injury which can result during donor organ retrieval and how these might be mitigated using new additives to organ preservation solutions (OPS), and (3) the scientific basis for machine perfusion of donor organs, which is becoming a new focus in the organ preservation pathway.

\section{Historical Perspectives of Organ Preservation for Transplantation}

A central focus for organ preservation has been to match the need to transport donor organs from the center where surgical retrieval has been performed to the implanting center, which may be many kilometers distant,

\section{KARGER}

(C) 2019 S. Karger AG, Basel 
and the potentially harmful functional consequences of hypoxia once the organ has been deprived of normal blood supply. Cooling is an intuitive way to reduce metabolic demand, but applying it to organs ex vivo and in a ways which could be readily reversed on transplantation, across a range of abdominal and cardiothoracic organs, required considerable research and development. Early in the 20th century, attempts to produce artificial circulatory support to perfuse organs in vitro were developed in systems such as the kidney and liver by simple syringe methods and provided detailed information on the physiology of organ function [6]. In parallel, efforts were made to formulate synthetic perfusate solutions of electrolytes, solutes, vitamins, etc. capable of replacing blood in some respects $[7,8]$. At the same time, information on the impact of hypothermia on organ function was also starting to be recorded [9].

Early investigations on the use of hypothermia in organs subsequently transplanted were undertaken by $\mathrm{Cal}$ ne et al. [10] in the kidney. They investigated the relative merits of cooling kidneys by simple surface cooling or by perfusion of the renal artery with cooled heparinized blood and concluded that vascular flush perfusion was the preferred method of cooling. However, the use of diluted blood in this way still led to problems with early vascular stasis in the grafted kidney, promoting the search for better OPS, preferably synthetic solutions which could be reliably manufactured and sterilized to be available at short notice as required [11]. The OPS described by Collins et al. [12] was designed to mimic, in a simple fashion, the intracellular electrolyte balance, which was in turn based on an understanding of the ongoing changes in cells during hypothermic and hypoxic exposure. This solution became a mainstay of clinical organ preservation for almost two decades. Successful renal preservation was achieved for up to 1 day, long enough to allow transplant tissue matching and sharing of organs over a wide geographic area. Alongside these approaches, proponents of continuous hypothermic machine perfusion (HMP) continued to develop methods for use of bloodless perfusates in oxygenated low-temperature perfusion across a range of organs [13-15]. However, the logistics and reliability of the available equipment meant that gradually, flush cooling and ice storage with synthetic OPS became the most widely used preservation method and allowed techniques for multiple organ retrievals from a single donor to be developed using the so-called "flexible techniques" [16] in which all organs designated for transplantation are cooled in situ, rapidly removed in a bloodless field, and further dissected on a back table. Following on from Collins et al.'s [12] work, other formulations of commercially produced OPS came forward based on progressive research into organ cold hypoxia. For example, Ross et al. [17] developed an intracellular mimic based on citrate as the major anion. Later, Belzer et al. [18] proposed another formulation with improved buffering and anion composition, which became known as the University of Wisconsin (UW) solution and remains in wide clinical application today. These will be discussed in greater detail below.

Since that time, it will be apparent that there is a fundamental choice to be made in organ preservation; whether to sustain ex vivo circulation by HMP and to supply oxygen to sustain low-level oxidative organ metabolism, or whether to use OPS to protect against the progressive hypoxia in the isolated organ during static cold storage (SCS) whilst using inexpensive and readily transportable ice storage of the cold-flushed, sterile-packed organ. For many years, the choice of SCS has dominated clinical organ preservation, but currently there is growing interest once more in dynamic intervention by organ perfusion, driven by many factors, including changing donor demographics and the need to utilize all available organs for transplantation to meet the rising clinical need. Recent publications continue to debate these issues [19-21].

\section{Ischemia/Reperfusion Injury as a Major Focus in Organ Preservation}

\section{Regulatory Mechanisms of Cellular Injury}

Historically, the development of effective OPS has always been accompanied by a deep focus on the mechanisms and strategies to attenuate ischemia/reperfusion (I/R)-induced cellular injury. Preservation methods and choice of solutions have an impact on organs across a diverse range of molecular response, thus providing crucial information about the timelines of processes to develop injuries and their physicochemical variations in relation to the OPS used (see The Central Role of OPS in Organ Preservation for more detail). In this case, special importance is given to the cellular and intracellular machineries under the pathological conditions of hypoxia. On the one hand, the cellular compartments are compromised by the duration of the ischemic period, donor age, trauma, existing infection, or other factors. On other hand, cellular heterogeneity, reflecting the organ complexity, influences profound imbalances in metabolism during I/R. The studies performed over the last three decades using isolated cell systems have significantly broadened our understanding of I/R, yet many pathophysiological aspects of the intercellular cooperation in tissue are still far from a unified understanding.

Experiments with I/R clearly demonstrated that severity of the injury after reperfusion directly correlated with the interval of ischemia. Hence, restoration of blood supply to the organ in the shortest possible time is essential. The general paradigm of the cellular reactions upon $I / R$ 
may reflect a picture of the sterile inflammation phenomenon [22]. This inflammation is predominated by the sentinel pattern recognition receptor systems [23] and involves complex reactions such as reactive oxygen species (ROS), leukocyte and platelet sequestration to the endothelium [24], transmigration of neutrophils, and the release of endogenous inflammatory mediators.

\section{Microvascular Dysfunction and Immune Cell \\ Response in I/R-Induced Inflammation}

Microvascular dysfunction is an early factor in the pathogenesis of I/R injury (IRI) and forms the basis for elaborating the underlying mechanisms of this pathological process. This type of injury is most frequently associated with SCS. Studies of rat liver transplantation demonstrated the crucial role of the onset of blood cessation in the development of IRI, bringing into question early microvascular impairment as a prognostic parameter for the assessment of early graft function in clinical practice [25]. It has been demonstrated that even a short duration of 20 min warm ischemia in the liver results in decreased sinusoidal diameter, which is associated with "plugging" of leukocytes upon reperfusion, as well as sinusoidal obstruction caused by endothelial cell swelling [26]. In contrast, cold ischemia protects from hepatic microcirculatory perfusion failure after $90 \mathrm{~min}$ of lobar ischemia [27]. However, prolongation of hypothermia to $24 \mathrm{~h}$ significantly reduced sinusoidal perfusion rates [28].

The mechanical and functional basis of microvascular reflow impairment after $\mathrm{I} / \mathrm{R}$ was attributed to a series of interrelated events which share common characteristics in different organs. These include interstitial edema formation due to increased capillary permeability [29] when interstitial tissue pressure may physically compress the capillaries and microvascular spasm [30] caused by vasoactive substances.

Some preservation solution compositions impart a vasoactive property and affect tissue microcirculation during I/R. For instance, flushing the organ with low-potassium medium prior to preservation may protect microvessels from the adverse effects of cold storage and improve reperfusion after transplantation in situations where vasoconstriction might be caused by a high potassium content in the OPS. Liver flushing with the OPS histidine-tryptophan-ketoglutarate (HTK), which is known to be low in $\mathrm{K}^{+}$ions, prior to organ storage in UW solution improved hepatic microcirculation and reduced sinusoidal leukostasis [31]. Another approach shows that a rinse with the low-potassium solution after cold storage prior to organ implementation substantially diminished postoperative sinusoidal endothelial cell damage. It was concluded that the synergistic action of UW solution as OPS and the Carolina Rinse solution as rinsing vehicle was more beneficial for the vascular bed than each solu- tion used separately $[25,32]$. This finding provides some arguments in favor of removal of high- $\mathrm{K}^{+}$-containing solution before transplantation.

The "no-reflow" phenomenon in $\mathrm{I} / \mathrm{R}$ is attributed to leukocyte plugging of the capillary lumens. Leukocytes are large and stiff cells which adhere to vascular endothelium and are more likely to become captured in capillaries, thereby obstructing luminal flow. Heart and kidney I/R models have demonstrated presence of leukocytes in a very high proportion in occluded capillaries. Additionally, the impact of hemodynamic forces upon reperfusion has also been implicated in the adhesion of leukocytes and further impairment of endothelial cells [33]. Perfusing the organ with hypertonic saline-dextran solution decreased endothelial cell swelling and inhibited neutrophil adhesion [34], which can form part of therapeutic strategies to restore the normal capillary network [35].

Discovering the role of gas mediators such as hydrogen sulfide $\left(\mathrm{H}_{2} \mathrm{~S}\right)$, carbon monoxide $(\mathrm{CO})$, and nitric oxide $(\mathrm{NO})$ is regarded as a milestone in organ preservation and transplantation, and they are promisingly considered to be effective in the protection of the endothelium during organ storage. In particular, across the wide spectrum of signaling functions, these molecules came out to be potent anti-platelet adhesion and anti-inflammatory substances [29], modulating the relaxation of stellate cells and improving the microcirculation of hepatic sinusoids [36]. It has recently been shown that endogenous $\mathrm{H}_{2} \mathrm{~S}$ regulates many physiological processes, including vascular tone. Additionally, $\mathrm{H}_{2} \mathrm{~S}$ was shown to interact with $\mathrm{NO}$ and form another potent vasorelaxant - nitroxyl [37].

After leukocyte plugging, the adhesion cascade is another major molecular process of leukocyte recruitment during an inflammatory response in I/R. Leukocyte adhesion with postcapillary venular endothelium initiates by forming loose contacts (leukocyte rolling). The sticking of leukocytes to the endothelium is mediated primarily by transmembrane adhesion receptors - integrins, selectins, vascular cell adhesion molecule-1 (VCAM-1), intercellular adhesion molecule-1 (ICAM-1) - responsible for adhesion of cells and extracellular matrix and rolling. Recent studies have challenged the potential therapeutic significance of $\alpha 4 \beta 1$ integrin receptors ( $\beta 1$ integrin family), which binds with the connecting segment-1 (CS-1), a V region of fibronectin. The latter is a key extracellular protein expressed by sinusoidal endothelial cells in the early beginning of liver ischemia [38]. Blockage of $\alpha 4 \beta 1$-CS- 1 region interaction with a specific peptide resulted in an increase in survival (from 40 to 100\%) for 14 days after orthotopic liver transplantation as well as a reduction in TNF- $\alpha$ and IFN- $\gamma$ expression as well as T-lymphocyte and leukocyte sequestration [39].

Interactions between integrin receptors [40] and other adhesion molecules like VCAM-1, ICAM-1, and P- and 
E-selectins reveal a complicated and tissue-specific regulatory mechanism of leukocyte adhesion and extravasation. For instance, in comparison with lungs and heart, liver sinusoidal endothelium neutrophil tethering and "crawling" does not exhibit strict dependency of P-selectin/integrin assistance $[41,42]$. However, neutrophil extravasation from the hepatic microcirculation into the parenchyma is facilitated by $\beta 2$ and $\beta 1$ integrins [43], showing their direct contribution to ligands/counterreceptor participation in neutrophil transmigration. Interestingly, neutrophil extravasation through pericyte gaps into the parenchyma corresponds to regions with low contents of specific matrix proteins in the basement membrane. It could be hypothesized that the cold-induced decrease in endothelial junctional proteins such as F-actin, occludin, and VE-cadherin [44] may be responsible not only for the development of organ edema, but also for extravasation of neutrophils [45]. The influence of OPS on the expression of adhesion molecules could provide additional information in relation to recruitment of immune cells in inflammation during organ reperfusion. Comparative studies of HTK and UW solutions have shown much lower expression of P-selectin in the UW solution group, which demonstrates a significant benefit over HTK [46].

\section{Kupffer Cells and Macrophages in $I / R$}

Kupffer cells are resident macrophages of hepatic sinusoids which are well known to be a powerful source of ROS, proteases, platelet activating factor, and cytokines during I/R. Activated Kupffer cells begin to produce proinflammatory cytokines, such as IL- $1 \beta$ and TNF- $\alpha$, promoting the migration of neutrophils and CD4+ T lymphocytes with the subsequent development of inflammation in the parenchyma.

A growing body of data demonstrate that Kupffer cells are an important participant in the development of sterile inflammation mediated via Toll-like receptors (TLRs), which are a significant part of signaling pathways in sentinel cells. In contrast to pathogen-activated inflammation, TLRs are triggered by intracellular factors and fragments of extracellular matrix, named damage-associated molecular patterns (DAMPs), which are released from ischemically injured cells. DAMPs are recognized by the innate immune cells (macrophages, leukocytes, and dendritic cells) as well as vascular cells (fibroblasts and endothelial cells) to promote proinflammatory and profibrotic pathways [47].

DAMPs include high-mobility group box-1 (HMGB1), DNA of mitochondria and nucleus, purine metabolites, hyaluronan, and others. Despite the fact that the precise regulatory mechanism of Kupffer cell activation is yet to be fully unveiled, the current experimental data amply demonstrate interrelation between Kupffer cell/TLR liga- tion and subsequent complement activation, ROS formation, neutrophil recruitment, and platelet aggregation. The prominent role of TLR-4 triggering was confirmed in orthotopic liver transplantation models. Knockout mice deficient in liver TLR-4 had significantly lower liver expression of TNF- $\alpha$, myeloperoxidase, aspartate aminotransferase, and CD4+ T cell infiltration $[48,49]$. In a model of renal inflammation, ischemia-induced synthesis of TLR-2 and TLR- 4 was substantially attenuated by inhibition of cytokine production with IFN- $\gamma$ and TNF- $\alpha$ antibodies pretreatment. Similarly, inhibition of HMGB-1 - a nuclear and cytoplasmic ligand for TLR-2 and TLR-4 - decreased liver injury after cold storage and warm reperfusion [50]. This feature demonstrates the possible reciprocal regulation of pro-/anti-inflammatory factors and TLRs. Translation of inflammatory signals from TLR sustains feedback with target cells, resulting in suppression or activation of TLR expression. Future research in TLR function can provide a new basis for the development of ligand-receptor-mediated drugs for limiting IRI.

Kupffer and other immune cells in the inflammatory response caused by either warm or cold ischemia display high regulatory plasticity. In addition to ROS and cytokine production, there is evidence of the anti-inflammatory function of macrophages and Kupffer cells in hememediated injury. The scavenging of free hemoglobin from plasma is controlled by expression of the CD163 receptor on the surface of macrophages and monocytes. The endocytosis of hemoglobin via CD163-dependent internalization also stimulates the production of heme oxygenase-1 (HO-1) in macrophages followed by degradation of toxic heme $[51,52]$. The HO-1-induced breakdown of hemoglobin is accompanied by $\mathrm{CO}$ release, known to possess strong anti-inflammatory and proangiogenic properties [53]. Another important aspect of Kupffer cells is the induction of apoptosis and removal of peripheral blood leukocytes during the tissue regenerative process [54]. Consequently, similar to other macrophages [55], Kupffer cells play a dual role; in early reperfusion they intensify and at the later stages subside the inflammation to assist tissue healing.

\section{The Role of Platelets in Organ IRI}

Platelet aggregation during hemostasis is regularly described as a privileging process of blood coagulation in the vascular defense against trauma. However, the decrease in platelet numbers due to their sequestration in organs after cold storage has apparently been considered a potential risk in organ transplantation. A closer look at this problem shows a lack of evidence for platelet adhesion to vascular endothelium [56]. For example, after $24 \mathrm{~h}$ of cold storage of liver in UW solution and subsequent normothermic reperfusion, there were no obvious 
clot formations or vessel occlusions observed. Therefore, it has been concluded that platelet-induced endothelial cell injury is probably not related to their procoagulant properties.

During past decades, the information about the role of platelets in IRI has been revised and supplemented. There is compelling evidence to suggest that platelets participate in endothelial cell adhesion in cooperation with neutrophils and lymphocytes to initiate innate immune responses under different pathological conditions. Activated platelets were shown to stimulate neutrophil/macrophage ROS production, control endothelial permeability, and promote neutrophil infiltration. The hallmark of platelet-endothelial cell adhesion is the formation of a matrix which includes neutrophil extracellular traps, and P-selectin mediated leukocyte binding [57] that predominantly has negative consequences for the transplant functional state.

Activated platelets express a range of adhesion receptors, such as P-selectin (CD62P), TGF- $\beta$, PF4 (CXCL4), IL- $1 \beta$, and others, which predispose their interactions with immune cells, endothelial cells, and adhesion molecules. The list of platelet receptors as well as a sequence of events, including the mechanisms for their recruitment, is constantly being updated [58]. The recent finding of HMGB-1 protein in platelets shows their importance in the regulation of neutrophil extracellular trap formation and thrombosis [59] mediated via TLRs.

These varieties of signal transduction clearly encompass far more than the hemostatic or inflammatory functions of platelets and also expand the horizon for endeavors in the treatment of organ IRI. For example, the translational studies of regeneration and repair after $I / R$ suggest the participation of platelets in liver recovery after partial hepatectomy. The repairing effect of platelets could possibly be explained by contact or even uptake of cells by hepatocytes [60] and the release of insulin-like growth factor-1 (IGF-1), hepatocyte growth factor (HGF), vascular endothelial growth factor (VEGF), and serotonin from platelets, which together can promote hepatocyte proliferation [61]. Yet, further research is required to fully clarify the platelet regenerative potential following organ $\mathrm{I} / \mathrm{R}$.

It may be expected that platelet aggregation and adhesion originates not only from pathological changes in themselves. Cold-induced alterations of the microvascular environment may readily contribute to platelet activation. The direct contact with collagen of exposed subendothelial extracellular matrix, ADP release from damaged cells or due to inhibition of T-lymphocyte ectonucleotidase, and leukocyte cytokine production may be considered in the frontline of platelet adhesion and aggregation [62]. The balance between ROS and NO production serves as an alternative regulatory mechanism of platelet adhesion. It is extensively recognized that production of $\mathrm{NO}$ by endothelial cells prevents platelets adhesion. On the contrary, superoxide anion $\left(\mathrm{O}_{2}^{-}\right)$induces vascular adhesion of platelets and leukocytes. It is intriguing that $\mathrm{NO}$ can scavenge $\mathrm{O}_{2}{ }^{-}$much faster than superoxide dismutase does. Therefore, $\mathrm{O}_{2}{ }^{-}$overproduction after I/R may increasingly surpass NO bioavailability. Additionally, as was reported recently [63], modifications of endothelial NO synthase (eNOS), due to the loss of the enzyme cofactor tetrahydrobiopterin or/and eNOS uncoupling, makes production of ROS instead of NO possible.

Taken together, it is still controversial which of the factors predominate in platelet activation response. Understanding of the synergistic ways of intercellular regulation after cold storage will be essential for prevention of IRI [57].

\section{The Role of Endothelial Glycocalyx in IRI}

Degradation of the endothelial glycocalyx (GCX) has been implicated in several disease processes including sepsis, trauma, and IRI [64]. The GCX is a thin (60$570 \mathrm{~nm}$ ), fragile, and ubiquitously expressed "hair-like" layer on the luminal surface of all blood vessels and is responsible for vital physiological functions of the endothelium. This layer is composed of proteoglycan core proteins (such as syndecans and glypicans) with a transmembrane domain on the endothelial surface which are crosslinked with highly sulphated glycosaminoglycan chains (dermatan sulphate, heparan sulphate, chondroitin sulphate). Together, these form a thin protective "mesh" on the endothelial surface which incorporates plasma proteins and several biologically active molecules including albumin, superoxide dismutase, xanthine oxidoreductase, lipoprotein lipase, cytokines, endogenous heparins, and regulators of the coagulation pathway [65]. In I/R, the GCX layer is disintegrated through enzymatic cleavage of the proteoglycan core proteins and glycosaminoglycan chains or direct oxidative stress by ROS [65].

The complex mesh formed by the GCX is an important determinant of vascular permeability which acts as a sizeselective and charge-selective molecular sieve allowing small solutes $(<70 \mathrm{kDa})$ and water to pass but repels negatively charged plasma proteins to the center of the lumen. It is now widely accepted that the GCX is primarily responsible for the all-important semipermeability function of the endothelium [66]. The classical Starling principle of transvascular exchange has been revised to consider the presence of the GCX and more accurately describe fluid exchange in the microcirculation [66]. Disruption of the GCX in inflammatory states leads to vascular hyperpermeability and edema [67].

The endothelial GCX acts, amongst other sensors, as a mechanotransductor to transmit flow-induced shear forces to the endothelial cytoskeleton, triggering $\mathrm{NO}$ pro- 


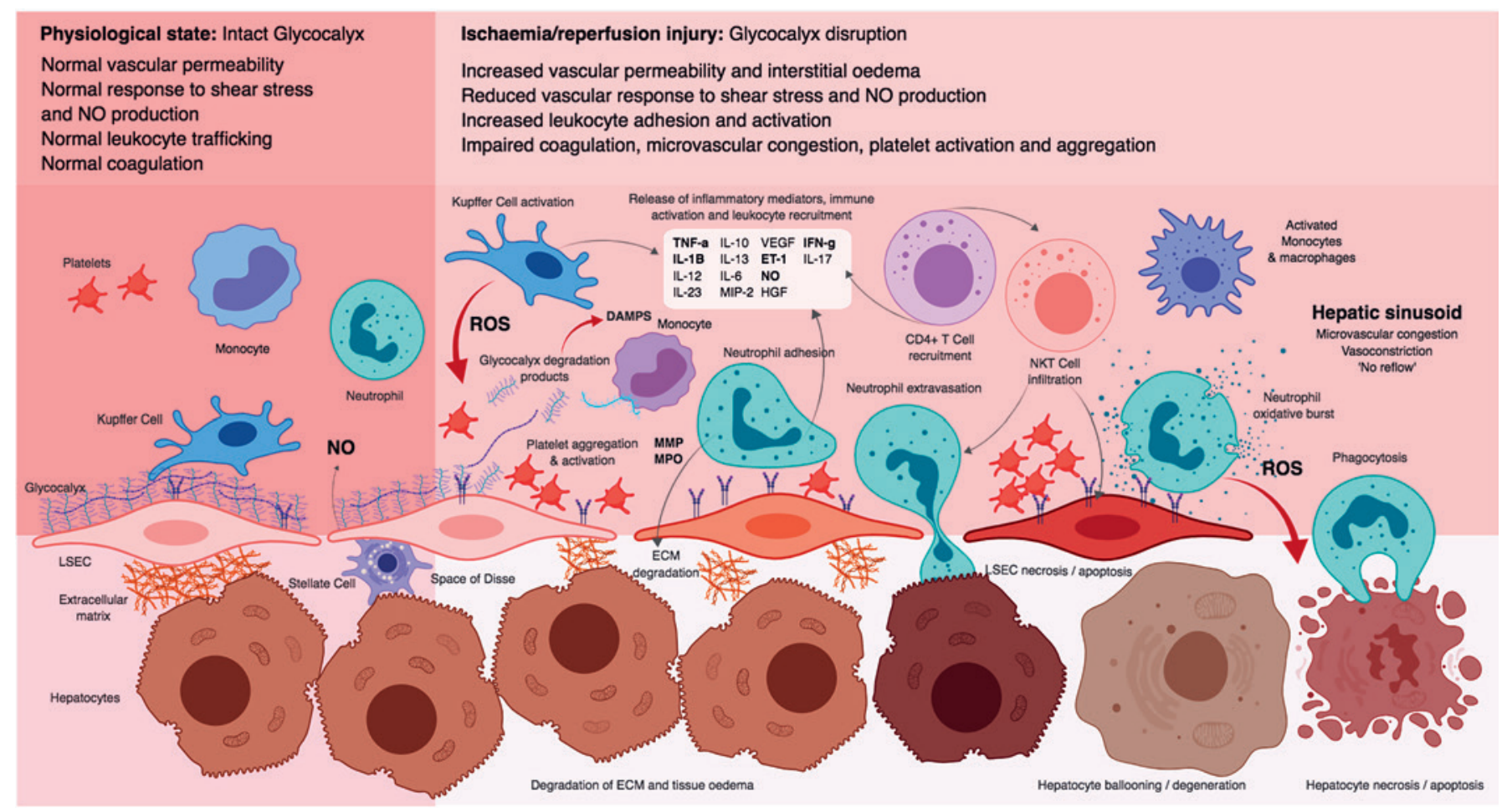

Fig. 1. In a physiological state, the healthy GCX maintains normal vascular permeability, response to shear stress, and NO production. Early events in IRI include activation of Kupffer cells and ROS and cytokine production which cause direct or indirect damage to the endothelial GCX in the hepatic sinusoid. This results in increased platelet and leukocyte adhesion as well as a loss of vascular permeability leading to tissue edema. The GCX degradation products act as DAMPs, further exacerbating the inflammatory response with the release of cytokines and recruitment of inflammatory cells (neutrophils, macrophages, $\mathrm{CD} 4+$, and natural killer $\mathrm{T}$ cells) to the liver after reperfusion. The combined effects of tissue edema, microvascular congestion from platelet and leukocyte aggregation, and direct effect of inflammatory cells lead to liver sinusoidal and hepatocyte cell death. DAMPs, damage-associated molecular patterns; GCX, glycocalyx; IRI, ischemia/reperfusion injury; NO, nitric oxide; ROS, reactive oxygen species. duction, which plays an important protective role in the microcirculatory function in IRI. As well as a major determinant of vascular tone, NO has several endothelial protective functions through inhibiting intracellular calcium increase in platelets, thereby preventing activation and thrombosis as well as inhibiting monocyte proliferation and the transcription of leukocyte-binding adhesion molecules (such as VCAM-1). Defective endothelial mechanosensing results in a reduction in eNOS activity causing decreased NO release and antioxidant defense. Liver steatosis is a major risk factor for graft failure in liver transplantation mainly due to microcirculatory disturbances. It has recently been demonstrated that steatotic livers have a poor response to shear stress, which is an important function of the GCX. Steatotic livers had a reduced level of eNOS activity and NO production as well as decreased Kruppel-like factor 2 expression under subnormothermic perfusion [68]. In a recent study of steatotic rat liver preservation, it was shown that Institut Georges Lopez-1 (IGL- $1^{\circledR}$ ) preservation solution produced less GCX injury over HTK, which was associated with significantly reduced hepatocyte damage and higher
NO production after $24 \mathrm{~h}$ of SCS [69]. Therapeutic strategies in GCX protection during organ preservation could potentially enhance the organ viability of marginal donors and reduce the severity of IRI.

The GCX also provides vascular protection by "shielding" the endothelial cells from interaction with circulating platelets and leukocytes - the so-called "immune camouflage" effect. The projections of cell surface adhesion molecules such as selectins (platelet endothelial cell adhesion molecule, VCAM), ICAM, and integrins (CD11/ CD18) are physically shorter than the thickness of a healthy GCX in vessels [70], which inhibits firm adhesion of platelets and leukocytes. Reduced platelet and leukocyte adhesion has been demonstrated with GCX protection in I/R models of isolated guinea pig hearts [71, 72]. Furthermore, degradation of the GCX in cultured endothelial cells under flow has been shown to induce a proinflammatory phenotype and to increase leukocyte adhesion [73]. Shedding of the GCX layer leads to a vicious cycle of inflammation in two ways. First, a reduction in GCX thickness leaves cell surface adhesion molecules exposed to circulating inflammatory cells and platelets, 
which may further facilitate ligand-receptor interactions leading to release of cytokines, matrix metalloproteases, and ROS which cause further GCX shedding [74]. Second, the inflammatory response can be exacerbated by the circulating degraded fragments of the GCX which have been characterized as DAMPs resulting in cytokine release when binding to TLR receptors on macrophages, dendritic cells, and endothelial cells [75] (Fig. 1).

There is a significant rise in GCX shed products at reperfusion [76] during liver transplantation. It is not clear whether the substantial rise in the recipient circulating GCX products is due to flushing of the shed GCX from the donor liver that has already occurred in preservation or secondary to GCX shedding in the recipient due to reperfusion injury. Given its vital physiological functions, GCX damage could be responsible for several posttransplant complications. A recent large clinical study of patients admitted to the intensive care unit with sepsis showed that GCX shedding is more severe in patients with acute respiratory distress syndrome and multiple organ failure [77]. Significant GCX disruption in patients with hemorrhagic shock secondary to trauma is associated with the development of coagulopathy and increased mortality [78]. Prevention of local and systemic GCX disruption could potentially provide a novel unifying target to markedly reduce many of the direct and remote complications that arise as a result of IRI in the recipient, as well as provide opportunities for donor organ resuscitation during organ preservation.

\section{The Central Role of OPS in Organ Preservation}

In reality, the choice of OPS, and the science underpinning their development, are central to organ preservation, whether HMP or SCS are to be used [79]. Ischemia comes at a huge cost to all cells with aerobic metabolism, resulting in cellular injury via a complex and interconnected chain of numerous failing mechanisms essential for homeostasis culminating in cell death. Although cooling initially suppresses the metabolic rate, prolonged cold ischemia leads to depletion of cellular adenosine triphosphate (ATP) and accelerated glycolysis as well as lactic acid production. The accumulation of adenine breakdown products such as hypoxanthine initiate oxygen free radical production. Cellular acidosis interrupts $\mathrm{pH}$ - and energydependent cellular processes including transmembrane ion pumps $\left(\mathrm{Na} / \mathrm{K}^{+}\right.$and $\left.\mathrm{Ca}^{2+}\right)$ which ultimately lead to influx of ions $\left(\mathrm{Na}^{+}\right.$and $\left.\mathrm{Cl}^{-}\right)$and water, causing loss of membrane potential and progressive cell swelling. Cell membrane injury occurs as a result of the release of lysosomal enzymes in response to intracellular acidosis and direct oxidative damage from free radicals. The activation of harmful proteases and phospholipidases caused by in- creasing levels of intracellular $\mathrm{Ca}^{2+}$ due to membrane pump failure results in mitochondrial membrane injury with the appearance of mitochondrial permeability transition pores and the release of cytochrome $\mathrm{C}$ initiating cell death by apoptosis. The combined effect of increase in intracellular acidosis, activation of lysosomes, increasing levels of free $\mathrm{Ca}^{2+}$ and $\mathrm{Fe}^{2+}$ pools, and mitochondrial dysfunction contribute to a pro-oxidant environment which fuels ROS production and oxidative stress at early reperfusion. This basic understanding of the mechanisms of cell injury in cold preservation underpins the biochemical properties of preservation solutions which aim to target putative pathways mitigating the processes that lead to cell death. Hence, the constituents of OPS include impermeants and colloids to counteract water and electrolyte movement across cell membrane and prevent cell swelling, buffers to control changes in $\mathrm{pH}$, antioxidants in the form of free radical scavengers, as well as nutrient precursors for ATP production and energy supply.

Early developments in OPS by Collins et al. [12] were based on impermeants with an "intracellular ion balance" through reversal of $\mathrm{Na}^{+} / \mathrm{K}^{+}$ratios found in plasma. This was later refined with the addition of glucose as an impermeant and removal of magnesium in the Collins C2 solution. The UW solution has a similar intracellular ion balance with the added benefit of a colloid (hydroxyethyl starch [HES]) and pharmacological agents such as allopurinol (xanthine oxidase inhibitor), lactobionate and glutathione (free radical scavengers), as well as adenosine, a precursor for ATP production. IGL- $1{ }^{\circledR}$ solution is based largely on UW solution, but has an ionic balance close to the extracellular ratios of $\mathrm{Na}^{+} / \mathrm{K}^{+}$and a less viscous colloid (polyethylene glycol [PEG]). The Celsior ${ }^{\circledR}$ solution also has an extracellular ion balance and contains mannitol as well as histidine and reduced glutathione. HTK or Custodiol ${ }^{\circledR}$ includes histidine and mannitol as impermeants with tryptophan and ketoglutarate as free radical scavengers and nutrient precursor, respectively. The TiProtec solution is based on the HTK formulation with a higher fractional ion content, $\alpha$-ketoglutarate and aspartate as metabolic intermediates, and iron chelators to prevent iron-catalyzed oxidative stress.

Over the last decade, there has not been a great change in the composition of OPS. With the developments in the field of machine perfusion and organ resuscitation to improve the viability of marginal organs, there is a greater need for the development of new OPS.

\section{New Areas of Focus in OPS}

\section{Mitochondria-Targeted Antioxidants}

Cold preservative solutions, described in a previous review [80], namely Euro-Collins, UW solution (Via- 
$\left.\operatorname{span}^{\circledR}\right)$, Celsior ${ }^{\circledR}$, Custodiol ${ }^{\circledR}$, or IGL- $1^{\circledR}$, have been widely used in both experimental and clinical transplantation. Each of them has positive and negative features and provides similar storage time of donor organs [19, 81]. There is no consensus about the optimal preservation solution up to now. To extend organ preservation time and maximize the yield of successful transplantations by improving the quality and function of organs, the composition of preservation solutions should be further optimized. A promising approach is inclusion of agents in preservation solutions with targeted mechanisms of action.

IRI is largely triggered by mechanisms that involve oxidative stress accompanied by accumulation of ROS. Mitochondria are considered one of the main producers of ROS during cold storage and reperfusion, and correspondently play a key role in IRI of organs. Hence, supplementation of preservation solutions with antioxidants directed at the mitochondria to prevent their dysfunction should minimize organ damage.

Antioxidants are common components of cold preservative solutions. In UW solution and IGL- ${ }^{\circledR}$, antioxidant activity is associated with a combination of allopurinol and glutathione. In IRI, allopurinol acts as an inhibitor of xanthine oxidase, suppresses the formation of ROS, and prevents mitochondrial membrane damage [82]. Glutathione, which is also a component of Celsior ${ }^{\circledR}$, is a wellknown natural antioxidant and cellular redox buffer. Due to its redox properties and participation in cellular redox homeostasis and signaling, glutathione is now also considered in therapeutics as a tool for stimuli-responsive drug delivery systems [83]. In Custodiol ${ }^{\circledR}$, the protection against oxidative stress is provided by tryptophan, which shows a high scavenging capacity [84]. Mannitol is a component of Celsior ${ }^{\circledR}$, Custodiol ${ }^{\circledR}$, and other solutions. Besides its osmotic effect, mannitol also plays an antioxidative role via upregulating the level of catalase which is otherwise decreased during oxidative stress [85].

Rauen and de Groot [86] found a specific cold-induced increase in the small intracellular iron pool that is responsible for production of high reactive hydroxyl radicals and iron-oxygen species. Chelation of the iron by deferoxamine and lipophilic membrane-permeable LK-614 protects the myocardium and endothelium against irondependent hypothermic injury [87]. The authors have developed TiProtec, a new preservation solution, in which the role of antioxidants refers to iron chelators $[88,89]$. TiProtec is the modified Custodiol ${ }^{\circledR}$ (HTK) solution, which besides iron chelators (deferoxamine and LK-614) contains higher potassium concentration, amino acids (L-glycine and L-alanine) to inhibit hypoxic injury, arginine to increase NO supply, and N-acetyl-histidine instead of histidine as a buffer. It has been previously shown that replacing histidine with $\mathrm{N}$-acetyl-histidine in Custo- diol ${ }^{\circledR}$ improved endothelial function in isolated rat aorta [87]. In several experimental systems, TiProtec has demonstrated promising results in preservation of hepatocytes, vascular endothelium, and smooth muscle cells after cold storage and a period of warm reperfusion. In a recent study [90], iron chelators ensured protection via inhibition of mitochondrial permeability transition. Addition of iron chelators to cold preservation solutions resulted in increased oxygen consumption rate and regeneration of ATP as well as preserved attachment ability of isolated rat hepatocytes after returning to normothermic conditions.

The intensity of ROS formation depends on the potential on the inner mitochondrial membrane. Consequently, mitochondrial production of ROS is nonlinearly related to the value of the mitochondrial membrane potential, with significant increments at values exceeding $150 \mathrm{mV}$ [91]. High values of the membrane potential are greatly dangerous, especially under conditions associated with oxidative stress. Mild uncoupling of oxidative phosphorylation is an approach to preventing hyperpolarization of the mitochondrial membrane. It has been proposed that the use of water-soluble uncoupler of oxidative phosphorylation 2,4-dinitrophenol (DNP) as a component of cold preservation solution will make it possible to lower oxidative injury of the liver [92]. Indeed, supplementation of sucrose-based cold solution with DNP resulted in decreasing ROS production in isolated livers after cold storage, uncoupler washout and, following normothermic reperfusion, preventing the inhibition of antioxidant enzyme activities, and improving morphology and bile secretion of the liver. The protective effect of DNP at the mitochondrial level involved a decrease in respiration rate in state 4 , an increase in respiratory control index, and prevention of ATP depletion. Although the existence of high values of mitochondrial membrane potential during hypothermic storage is not documented, these encouraging results stimulate a search for agents with the capacity for selective regulation of ROS production by mitochondria.

One of the current strategies for delivery of mitochondrial antioxidants includes their conjugation to lipophilic cations. Lipophilic cations take advantage of mitochondrial membrane potential to facilitate their selective targeting and accumulation within the mitochondrial matrix. Lipophilic cation triphenylphosphonium $\left(\mathrm{TPP}^{+}\right)$ conjugated with derivatives of ubiquinol (MitoQ) or plastoquinone (SkQ) are the most advanced mitochondriatargeted antioxidants [93]. The level of $\mathrm{TPP}^{+}$-conjugated antioxidants in mitochondria can be more than 1,000fold higher than its extracellular level [94]. Both mitochondria-targeted antioxidants, MitoQ and SkQ, are under intensive research and clinical trials, but they are not FDA-approved drugs so far. 
In animal models, Mito $\mathrm{Q}$ has demonstrated therapeutic potential in multiple diseases and pathologies: Alzheimer's disease, hypertension, type 1 diabetes, heart attack, sepsis, fatty liver disease, etc. [93]. The efficiency of SkQ has also been shown on numerous experimental models, including those accompanied by IRIs such as kidney and heart infarction and ischemic stroke [95]. SkQ has been used as a component of cold preservative solution for rat liver hypothermic storage [96]. Isolated rat livers were stored for $24 \mathrm{~h}$ at $4^{\circ} \mathrm{C}$ either with or without $1 \mu \mathrm{M} \mathrm{SkQ}$ followed by reperfusion for $60 \mathrm{~min}$ at $37^{\circ} \mathrm{C}$. The presence of SkQ in the storage solution significantly decreased production of ROS in the liver during cold storage and reperfusion. The addition of SkQ to the cold preservation solution improved energy production function of the liver, demonstrated by increased respiratory control index of mitochondria and ATP levels. SkQ exhibited a positive effect on the liver secretory function and morphology after hypothermic storage, as estimated from enhanced bile flow rate during reperfusion and partial recovery of organ architecture as well as state of liver sinusoids and hepatocytes. These results demonstrate that mitochondria-targeted antioxidants are promising components of preservation solution for correction of IRI of isolated organs during cold storage.

\section{Bioregulators}

Improvement of organ survival by treatment with bioactive molecules which enable regulation and modulation of metabolic pathways is an attractive strategy in organ transplantation. Bioregulators may vary in size and nature. The properties of small-molecule bioregulators (CO, $\mathrm{H}_{2} \mathrm{~S}, \mathrm{NO}$ ) are under intense study as discussed in Microvascular Dysfunction and Immune Cell Response in I/RInduced Inflammation and have been reviewed in relation to delivery in OPS [79]. Cytokines, growth factors, proteins, and other bioactive molecules can be obtained from different sources such as isolated cells, cellular extracts, and pharmaceutical products. Preclinical and clinical studies in the past decade have demonstrated the renoprotective properties of mesenchymal stem/stromal cells (MSCs) $[97,98]$. MSCs are multipotent stem cells that can be isolated from a variety of adult or fetal stromal tissues and have a multilineage differentiation potential and the ability to repair damaged tissues and organs after transplantation. The therapeutic action of MSCs is associated with paracrine effects of secretomes, microvesicles, and exosomes, which are involved in the transfer of proteins and miRNA to neighboring cells. In total, MSCs secrete a lot of bioregulators such as IDO, TGF- $\alpha$, TGF- $\beta$, prostaglandin E2, HGF, IL-6, IL-10, VEGF, and bFGF $[99,100]$. These and other not yet identified bioregulators have diverse actions, such as modulating the local immune system, enhancing angiogenesis, preventing ROS production and cell apoptosis, as well as stimulating survival, proliferation, and differentiation of resident tissue cells [101].

The implementation of MSC paracrine effects requires physiological conditions for synthesis and secretion of bioregulators. Therefore, for low-temperature preservation of organs, MSC-based therapy can be valuable on stages of preconditioning or after cold storage reperfusion. Thus, intratracheal MSC instillation after $8 \mathrm{~h}$ of cold storage $\left(4^{\circ} \mathrm{C}\right)$ significantly decreased cold ischemia-induced lung injury [102]. The requirement for a source of viable MSCs is a limitation and raises the speculation as to the use of their conditioned media or natural mixture of bioregulators from other sources instead of MSCs themselves. It has been shown that supplementation of UW solution with trophic factor mixture (IGFs, epidermal growth factors and nerve growth factor, bactenecin, and substance P) substantially increased viability and reduced the production of hydrogen peroxide by tubular cells of dog kidneys after 3 days of cold storage [103], protecting mitochondrial function and preventing apoptosis [104]. The presence of trophic factors enabled the prolongation of storage duration time (up to 6 days) and significantly improved posttransplant kidney function [105]. The efficiency of storage medium supplemented with such growth factors has also been shown in a pig allogenic liver transplantation model [106].

The effects of bioregulators present in fetal tissue cytosol (FTC) of mesenchymal-mesodermal origin have been studied on a model of rat isolated liver. The choice of this source was based on high percentage of stem and progenitor cells and similarity with the microenvironment of MSCs. The unique composition of bioactive molecules and trophic factors of fetal origin has demonstrated a high recovery in activity in several experimental systems [107-109]. It was shown that rat pretreatment with FTC for $4 \mathrm{~h}$ before long-term (24-h) liver cold storage followed by reperfusion for $60 \mathrm{~min}$ led to a decrease in free radical production and normalization of antioxidant enzyme activity [110]. The pretreatment also had a positive effect on ATP level and restored the activity of a key ATP-generating enzyme of glycolysis, pyruvate kinase, as well as increasing the level of succinate-dependent mitochondrial respiration after short-term hypothermic storage [109]. Recently, Cherkashina et al. [111] showed that FTC presence in a sucrose-based cold preservation solution stabilized pro-oxidant-antioxidant balance, which is impaired in liver after hypothermic storage for $24 \mathrm{~h}$ followed by reperfusion, and prevented the uncoupling of mitochondrial oxidative phosphorylation and ATP level decline. In addition to the observed biochemical changes, supplementation of cold preservation solution with FTC resulted in almost complete restoration of bile flow rate during reperfusion and normal- 
ization of organ morphology. It is interesting that the natural cocktail of trophic factors contained in FTC demonstrated a more powerful protective effect on cold ischemia-induced liver injury than epidermal growth factor and IGF-1 added separately or in combination to UW solution [112]. The great protective potential of bioregulators of fetal origin as components of cold preservation solution enforces identification of individual bioactive molecules and investigation of their mechanisms of action.

\section{Classification of Perfusion Techniques Based on Preservation Temperatures}

In the history of perfusion machines, different strategies and temperatures of perfusion have been cited without consensus between authors. Terms such as hypothermic, subnormothermic, or normothermic were frequently used to describe perfusion temperatures, and the absence of a standardized criterion to describe technical details led to great heterogeneity between studies. In 2016, a group of distinguished researchers in the field of liver preservation proposed a nomenclature of perfusion temperature ranges that facilitates the comparison of different studies, meta-analysis realization, and criteria homogenization [113]. Much work in this area has focused on liver perfusion, although the same broad concepts apply to other organs.

\section{Hypothermic Machine Perfusion $\left(0-12{ }^{\circ} \mathrm{C}\right)$}

Perfusion at this temperature range mainly reduces tissue metabolism and at the same time, through the preservation solution, provides the necessary metabolic substrates for ATP synthesis and removal of metabolic waste by washing the parenchyma and endothelium [114]. The proposed cutoff point for HMP at $12{ }^{\circ} \mathrm{C}$ is supported by the observation of numerous energy-dependent reactions of mitochondrial liver enzymes which exhibit significant rate changes at this temperature [113].

Accordingly, some of the benefits of HMP are minimization of cold ischemia injury, improvement of grafts viability, and protection against biliary lesions $[115,116]$. In the case of hypothermic oxygenated perfusion, it also provides the opportunity to restore mitochondrial redox activity and cellular energy status while the metabolism is still dampened by hypothermia [117]. HMP additionally reduces the inflammatory response preventing Kupffer cell activation and decreasing neutrophils and platelets activity during reperfusion [118] and is considered a safe technique because, in the case of machine failure, the graft simply returns to the standard cold storage conditions. On the other hand, the main disadvantage of HMP is that assessment of liver function "in real time" is not feasible with this method. For instance, the liver does not synthesize bile during hypothermia [119].

The first experience in humans was reported by Guarrera et al. [120] in 2010 with nonoxygenated hypothermic dual (portal vein and hepatic artery) perfusion of twenty standard donation after brain death (DBD) human livers. Twelve months after transplantation, the survival rate was $90 \%$, early allograft dysfunction occurred only in $5 \%$ of the patients, and the incidence of biliary stricture was $5 \%$.

Van Rijn et al. [121] tested dual hypothermic oxygenated machine perfusion over donation after cardiac death (DCD) livers. The biliary outcomes were also encouraging; none of the preserved livers required retransplantation for nonanastomotic biliary stricture, as opposed to 5 of 20 livers in the control group. In the largest HMP clinical trial performed, 50 recipients of extended DCD livers achieved superior outcomes compared with nonperfused DCD grafts and perfused DBD grafts [122].

\section{Midthermic Machine Perfusion $\left(13-24^{\circ} \mathrm{C}\right)$}

In view of the fact that the broad range of temperatures, between 12 and $33^{\circ} \mathrm{C}$, shows a great difference in the rate of metabolism, Karangwa et al. [113] considered more appropriate to subdivide this interval and proposed the term midthermic machine perfusion.

Midthermic and subnormothermic machine perfusion were proposed to achieve a balance between the deleterious effects of cold ischemia and the high metabolic requirements of normothermia [123]. Additionally, exposure of the graft to normothermic temperatures after a period of cold storage implicates a significant risk of oxidative stress burst.

The application of midthermic machine perfusion resulted in lower intravascular resistance, better conserved microcirculation, and stronger mitochondrial function, and these effects coincided with both a higher energy charge and bile production [119].

Bruinsma et al. [124] examined the impact of a 3-h midthermic $\left(21^{\circ} \mathrm{C}\right)$ perfusion on seven discarded livers. The grafts were gradually warmed, reaching the final temperature within $1 \mathrm{~h}$. Liver function and dysfunction parameters showed not only that there was no liver injury, but also significantly improved liver functionality.

\section{Subnormothermic Machine Perfusion $\left(25-34^{\circ} \mathrm{C}\right)$}

Graft perfusion between 16 and $25^{\circ} \mathrm{C}$ is possible without the presence of red blood cells. It simplifies the procedure and could reduce costs. This is feasible because perfusion at subnormothermic temperature diminishes the activity of the respiratory chain in mitochondria and decreases the demand of cellular energy [125].

In subnormothermic perfusion of pig livers, the hepatic and biliary injury was reduced in grafts harvested by DCD and steatotic livers [126]. In addition to the biliary 
improvements, lower serum levels of alkaline phosphatase were measured during the survival period in the group treated with subnormothermic machine perfusion compared with the control group. Improvement of the preservation protocols of marginal grafts has the potential to increase the donor pool and improve graft function after liver transplantation.

Controlled oxygenated rewarming is the most recent application of the perfusion machine, in which the perfusion begins at hypothermic temperatures and gradually increases to subnormothermia [127], improving restitution of cellular homeostasis and mitigating rewarming injury by an adapted increase in temperature and metabolism [118].

Controlled oxygenated rewarming has recently been applied clinically, with the successful transplantation of six DBD grafts accepted under "rescue allocation" criteria [128]. The controlled oxygenated rewarming group demonstrated a lower aspartate aminotransferase peak compared with controls and $100 \%$ of patient and graft survival at 6 months.

It is expected that subnormothermic ex vivo perfusion machines will play a cooperative role with other preservation techniques [129]. An example of this is the supercooling technique, which was used to preserve rat livers up to $96 \mathrm{~h}$ [130]. Supercooling was combined with subnormothermic machine perfusion [129] for the loading of cryoprotectants into the liver as well as postsupercooling rewarming. Prior to supercooling, researchers used subnormothermic perfusion to load isolated rat livers with a nonmetabolizable glucose derivative (3-O-methyl-D-glucose). Livers were supercooled avoiding intracellular ice formation and, at the end of supercooling, $3 \mathrm{~h}$ of subnormothermic perfusion was performed to achieve an adequate recovery period for the liver before orthotopic transplantation. The 3-month recipient survival in the group that received livers supercooled for $72 \mathrm{~h}$ at $-6^{\circ} \mathrm{C}$ was $100 \%$.

\section{Normothermic Machine Perfusion $\left(35-38^{\circ} \mathrm{C}\right)$}

The term normothermia usually refers to the physiological body temperature of the species used in the study, i.e., $37^{\circ} \mathrm{C}$ for human and rodent studies and $38^{\circ} \mathrm{C}$ in studies with porcine models. The idea underlying the technique is to replicate the normal metabolism of the liver outside the body, providing oxygen and essential substrates in an environment maintained at a normal temperature $\left(37^{\circ} \mathrm{C}\right)$, avoiding ischemia and hypothermia altogether [119]. One of the main advantages of normothermic machine perfusion is the opportunity to evaluate the viability of the organ before its transplantation [118] by measuring markers of hepatic metabolism (i.e., bile production and liver enzymes release). The difficulty lies in providing sufficient oxygen and other necessary substrates to prevent subsequent graft deterioration and bacterial contamination, which is more likely to occur in warm environments [123]. Typically, perfusates based on concentrates of red blood cells, plasma, nutrients, cofactors and insulin, antibiotics, electrolytes and buffers are required, which makes normothermic machine perfusion a complex and expensive procedure [124]. To avoid the use of human blood products, the interest in extracellular oxygen carriers or oxygen-carrying plasma expanders has increased [131].

The normothermic machine perfusion technology was initially developed to mitigate the negative effects of simple cold storage, but additional benefits have allowed its use for broader purposes [132]. Normothermic perfusion defatting seeks to augment the protective effect of perfusion by adding a pharmacologic "defatting cocktail" stimulating lipid metabolism. Use of a defatting cocktail reduced intracellular lipid content by $50 \%$ during $3 \mathrm{~h}$ of normothermic machine perfusion in steatotic rat livers [133]. Another additional benefit is the ability to extend the graft preservation times. In the first clinical series, Ravikumar et al. [134] demonstrated the feasibility of preservation over $20 \mathrm{~h}$ without compromising recipient outcome. Liu et al. [135] recently described the metabolic activity of a discarded human liver perfused for $86 \mathrm{~h}$ on ex situ normothermic machine perfusion. This is an important finding, since long-term preservation could provide an opportunity for tissue regeneration and organ reconditioning through pharmacological, immunological, and genetic interventions. As a demonstration of intact metabolism, bile production and lactate clearance were preserved until the end of $86 \mathrm{~h}$. The hepatic histology of the parenchyma showed completely healthy hepatocytes. One limitation of the work, worthy of mention, was the absence of a transplant.

Nasralla et al. [136] described the first multicenter randomized clinical trial in which normothermic perfusion was compared with SCS. A total of 170 livers were perfused in a normothermic machine and 164 preserved by SCS, and the authors reported the 1-year outcome for those successfully transplanted. There was a significant reduction in graft injury despite a 50\% lower rate of organ rejection and a $54 \%$ longer mean preservation time. There was also no advantage to be gained from using normothermic perfusion in terms of any major outcome measure, such as graft or patient survival or frequency of biliary complications. Mergental et al. [137] reported liver transplants after a period of normothermic perfusion to assess the viability of the rejected livers. They used these livers after a variable period of cold storage and reported encouraging results, with an average hospital stay of 10 days and graft survival in all recipients.

It is probable that in the near future, normothermic perfusion will be used to change the concept of preservation, to a concept of being a method of treatment and repair of organs [138]. 
Table 1. Determinations of the COP, osmolality, and viscosity of different preservation solutions

\begin{tabular}{llccl}
\hline & HTK & $\operatorname{Viaspan}^{\circledR}(\mathrm{UW})$ & BGP-CS & BGP-HMP \\
\hline $\mathrm{COP} 5^{\circ} \mathrm{C}, \mathrm{mm} \mathrm{Hg}(n=4)$ & $1.45 \pm 0.46$ & $31.90 \pm 1.63$ & $11.89 \pm 1.78$ & $4.35 \pm 0.24$ \\
Osmolality, $\mathrm{mOsm} / \mathrm{kg} \mathrm{H}_{2} \mathrm{O}$ & 310 & 324 & 303 & 290 \\
Viscosity $5^{\circ} \mathrm{C}, \mathrm{cP}(n=3)$ & $1.68 \pm 0.005$ & $5.01 \pm 0.007$ & $2.61 \pm 0.005$ & $1.68 \pm 0.010$ \\
\hline
\end{tabular}

COP, colloid osmotic pressure; HTK, histidine-tryptophan-ketoglutarate; $n$, number of measurements; UW, University of Wisconsin.

\section{Experimental Observations of Temperature on Liver Preservation Perfusion Protocols}

Liver hypothermic/midthermic/subnormothermic (H/M/S) perfusion effectiveness will depend on the following fundamental features: (1) Counteract cellular edema due to hypothermia: this phenomenon could be compensated by the inclusion of a cell impermeant substance into the perfusion solution [4]. (2) Prevent expansion of the interstitial space and subsequent compression of the vasculature that, during reperfusion, will generate an increase in intrahepatic resistance and vascular damage. With the inclusion of an oncotic active substance in the perfusion solution, it could be possible to control the water distribution between interstitial space and vasculature during perfusion [139]. (3) Provide adequate conditions for high-energy phosphate regeneration; therefore it will be possible to improve the function and viability of the liver during reperfusion. Accordingly, the addition of nucleotides and other substances into the perfusion solution could improve organ function and viability after the preservation procedure. (4) Supply an adequate gas atmosphere to obtain a lower oxidative metabolism, preventing the toxic effects of high oxygen concentrations in the perfusion solution [140].

Specifically, colloid osmotic pressure (COP) or plasma oncotic pressure represents the counterforce to the filtration pressure in the blood circulation and is therefore partially responsible for the water distribution between the vasculature and the interstitial space [141]. Its physiological value is approximately $25 \mathrm{~mm} \mathrm{Hg}$ and it was determined mainly by albumin concentration in the blood. For long-term perfusion experiments, oncotically active substances are essential to counteract interstitial edema, inevitably produced when these substances are not added to the perfusion solution.

COP could have effects on: (1) Variables such as the total $\mathrm{H}_{2} \mathrm{O}$ content of tissues and their distribution in intracellular and interstitial spaces during hypothermic perfusion. (2) Lower hydrostatic pressure gradient developed during the H/M/S perfusion procedures. (3) The same variables in the postperfusion period and their ef- fects on flow, intrahepatic resistance, tissue damage, and bile production.

It is possible to ask: which is the optimal COP of a solution for $\mathrm{H} / \mathrm{M} / \mathrm{S}$ perfusion procedures? Since it is necessary to maintain an appropriate intravascular fluid level in presence of a lower perfusion pressure than the physiological one, it is important to consider the inclusion of a colloid in the hypothermic perfusion solution, for which the following experiments were carried out.

The COP (expressed in $\mathrm{mm} \mathrm{Hg}$ ) was determined using a colloidal osmometer or oncometer at $20^{\circ} \mathrm{C}$ (Table 1). The optimal condition would have been the determination of the COP at low temperatures, but this is not possible yet because commercial equipment is not available. However, a temperature correction could be made by using an appropriate formula if one were available.

\section{COP Correction by Temperature}

Nearly all publications indicate that the COP was determined at room temperature $\left(20-25^{\circ} \mathrm{C}\right)$. Skillman and colleagues $[142,143]$ corrected this value to $37^{\circ} \mathrm{C}$, based on the work of Soto-Rivera [144], who used the Hepp osmometer to determine COP for comparison against plasma density.

The van't Hoff estimation for osmotic pressure is

$$
\pi=\mathrm{CRT}
$$

where $\mathrm{C}$ is the molar solute concentration, $\mathrm{R}$ is the ideal gas constant, and $\mathrm{T}$ is the absolute temperature (Kelvin). Then the effect of the variable temperature could be calculate as:

$$
\begin{aligned}
\pi_{\text {calculated }}= & \pi_{\text {measured }}\left[\left(273^{\circ} \mathrm{C}+\text { calculated temp. }{ }^{\circ} \mathrm{C}\right) /\left(273^{\circ} \mathrm{C}+\right.\right. \\
& \text { measured temp. } \left.\left.{ }^{\circ} \mathrm{C}\right)\right]
\end{aligned}
$$

in which $\pi_{\text {calculated }}$ and $\pi_{\text {measured }}$ represent the calculated and measured values, respectively, for $\pi$ at their corresponding temperatures in ${ }^{\circ} \mathrm{C}$.

If a COP determined at $20^{\circ} \mathrm{C}$ is $11.3 \mathrm{~mm} \mathrm{Hg}$, then the value at $5^{\circ} \mathrm{C}$ will be calculated as

$$
\begin{aligned}
\pi_{\text {calculated }}= & 11.3 \mathrm{~mm} \mathrm{Hg}[278 / 293]=11.3 \mathrm{~mm} \mathrm{Hg} \times 0.9488= \\
& 10.72 \mathrm{~mm} \mathrm{Hg} .
\end{aligned}
$$


Table 2. The systemic capillary forces

\begin{tabular}{lcc}
\hline & Systemic & $\begin{array}{l}\text { Hypothermic } \\
\text { perfusion } \\
\text { protocol }\end{array}$ \\
\hline Outward flow, $\mathrm{mm} \mathrm{Hg}$ & 17 & \\
$\mathrm{P}_{\mathrm{c}}$ & 5 & 4.2 \\
$\pi_{\text {isf }}$ & 6.3 & 5 \\
$\mathrm{P}_{\text {isf }}$ (negative) & 28.3 & 6.3 \\
Total & & 15.3 \\
\hline Inward flow, $\mathrm{mm} \mathrm{Hg}$ & - & - \\
$\mathrm{P}_{\text {isf }}$ (positive) & 28 & 15 \\
$\pi_{\mathrm{pl}}$ & 28 & 15 \\
Total & 0.3 & 0.3 \\
\hline Net outward pressure & & \\
\hline
\end{tabular}

In the following example, determinations were done by using an OSMOMAT 050 oncometer from GONOTEC with a semipermeable membrane of 20,000 Daltons cutoff.

Our group has been interested in developing a new group of OPS formulated on gluconate and the Good's buffer BES (N,N-bis[2-hydroxyethyl]-2-aminoethanesulfonic acid) with different colloids (e.g., BES gluconate HES-BG-HES [145]). Their physicochemical properties have been studied and compared with other traditional OPS [79]. Experimental COP values obtained for the newly formulated gluconate-based BG-PEG and BG-HES preservation solutions [145] were determined at different concentrations of two different colloids: PEG 35000 and HES used at $1,2,5,10$, and $20 \mathrm{~g} / \mathrm{L}$ at $20^{\circ} \mathrm{C}$. The results are presented in Figure 2.

At a similar colloid concentration, the COP developed by the PEG 35000 is higher than that of HES. In fact, using the obtained equations, it is possible to calculate the colloid concentration and obtain an appropriate COP in the perfusion solution.

Theoretical Calculations to Determine the Appropriate Concentrations of Colloidal Substances Which Produce COP Suitable for an H/M/S Perfusion Solution

Based on the classical Starling equation, the purpose of this study was to obtain an accurate and simple method for calculating the COP concentration to apply in an H/S protocol. We based this calculation on the graphic shown in Figure 2. These graphs were obtained plotting the COP measured at different concentrations of oncotic substances, such as PEG 35000 and HES, in BG-basic perfusion/preservation solutions at $20^{\circ} \mathrm{C}$.

The classical Starling hypothesis [146] can be expressed as:

$$
\mathrm{F}=\mathrm{K}_{\mathrm{f}}\left[\left(\mathrm{P}_{\mathrm{c}}-\mathrm{P}_{\mathrm{isf}}\right)-\left(\pi_{\mathrm{pl}}-\pi_{\mathrm{isf}}\right)\right]
$$

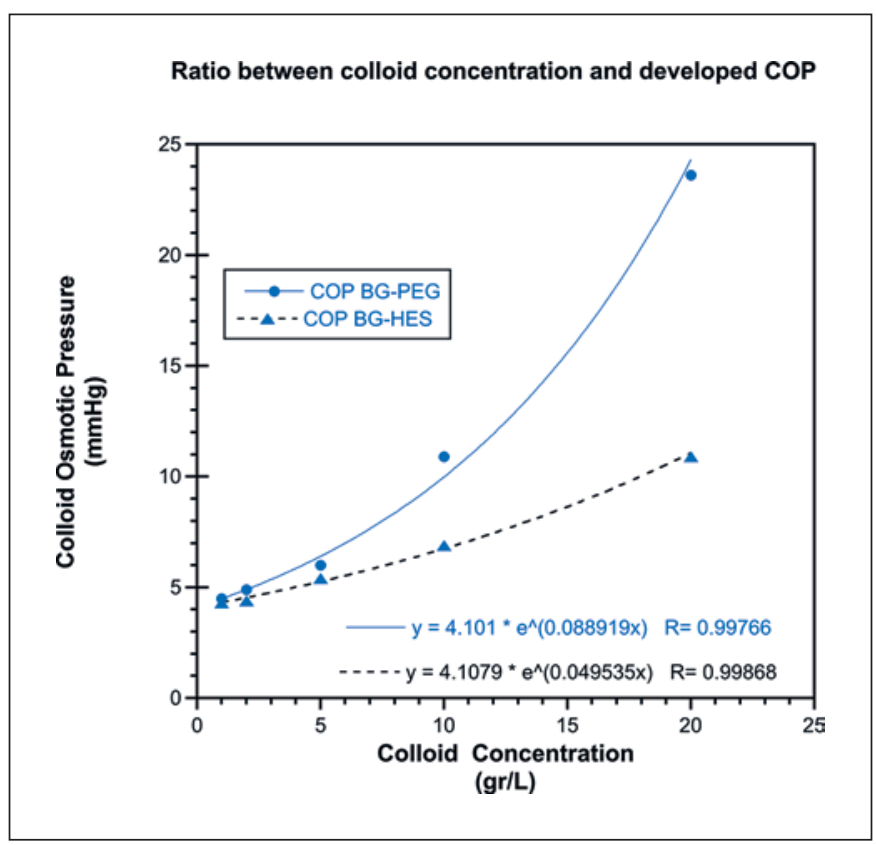

Fig. 2. Effect of PEG and HES concentration on BG-basic solution COP. Higher concentrations of PEG result in a major COP than the one observed for the same HES concentration. Data were fitted by an exponential equation. COP, colloid osmotic pressure; HES, hydroxyethyl starch; PEG, polyethylene glycol.

where $\mathrm{F}$ is the capillary filtration, $\mathrm{K}_{\mathrm{f}}$ is the membrane permeability component, $\mathrm{P}$ is the hydrostatic pressure, $\pi$ is the COP, $\mathrm{c}$ is capillary, pl is plasma, and isf is interstitial fluid. As was reported by Weisberg [141], the systemic capillary forces could be represented in a simplified frame, as shown in Table 2.

If we consider a hypothermic perfusion protocol in which the perfusion pressure is $25 \%$ lower $(4.2 \mathrm{~mm} \mathrm{Hg}$ ) than the physiological one, the calculated outward flow will be $15.3 \mathrm{~mm} \mathrm{Hg}$ (see hypothermic perfusion protocol in the frame). Then we should provide an oncotic substance that in the perfusion solution achieves a COP of $15.0 \mathrm{~mm} \mathrm{Hg}$.

The equation corresponding to PEG 35000 added into BG-basic solution shown in Figure 2 is:

$$
\mathrm{Y}=4.101 \mathrm{e}^{(0.0889 \mathrm{x})}
$$

where $\mathrm{Y}$ is the COP ( $\mathrm{mm} \mathrm{Hg}$ ) and $\mathrm{x}$ is the colloid concentration in $\mathrm{g} / \mathrm{L}$. Solving the equation, we obtain a PEG 35000 concentration of $14.81 \mathrm{~g} / \mathrm{L}$ necessary to develop a $\mathrm{COP}$ of $15 \mathrm{~mm} \mathrm{Hg}$ at $20^{\circ} \mathrm{C}$.

At $5{ }^{\circ} \mathrm{C}$ the value of calculated COP will be $14.40 \mathrm{~mm}$ $\mathrm{Hg}$ (see above), then it will be necessary to make a correction of PEG concentration (4\%), adding $0.59 \mathrm{~g} / \mathrm{L}$ of PEG, obtaining a final concentration of $15.40 \mathrm{~g} / \mathrm{L}$.

In order to compare BGP-HMP with other traditional preservation solutions [79], such as HTK [79, 147], BGP- 


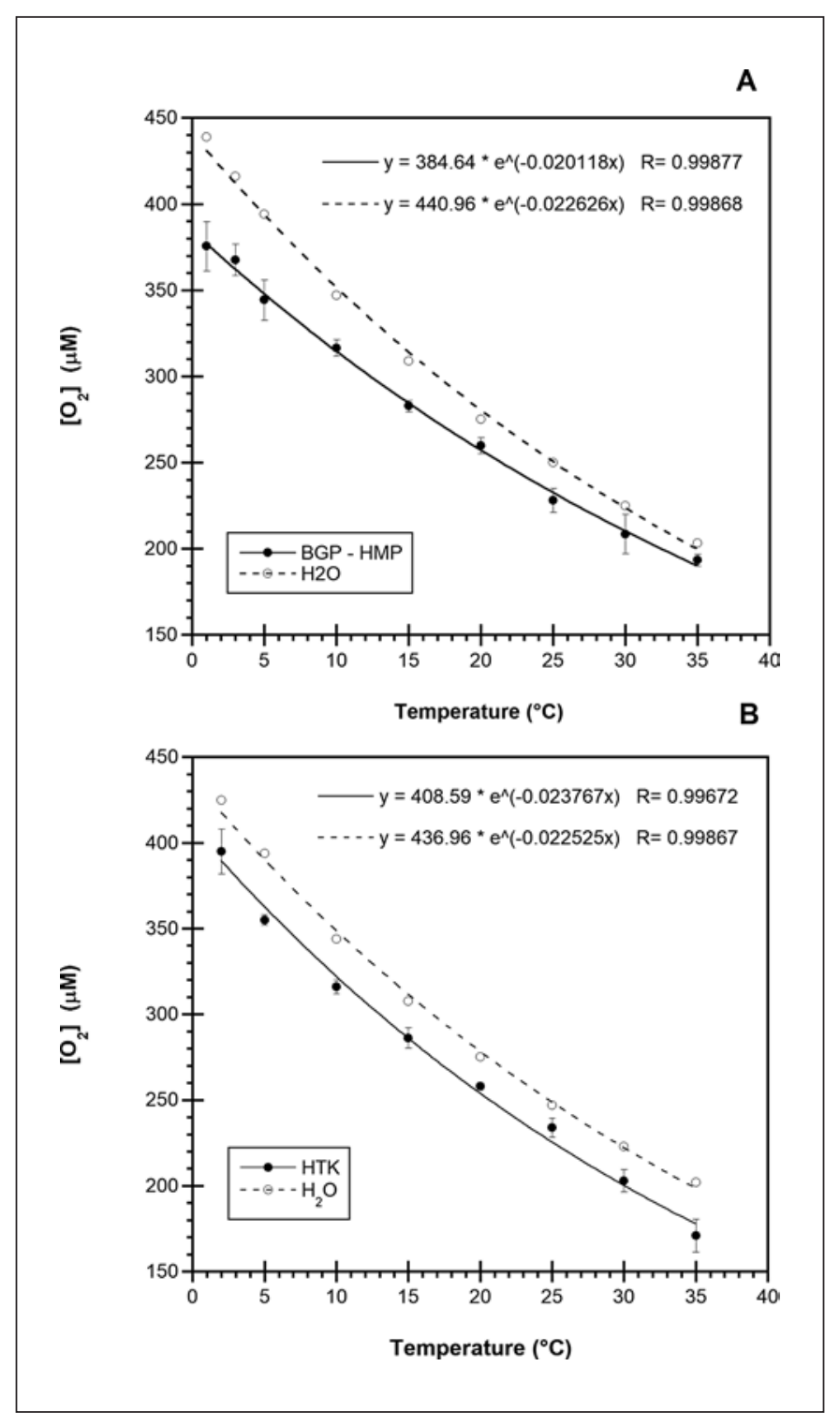

Fig. 3. Effect of temperature on oxygen-carrying capacity of BGPHMP and HTK solutions with respect to water. Oxygen solubility in fresh water and BGP-HMP solution (A) or HTK solution (B). Oxygen solubility values in pure water were taken from the literature and a barometric pressure of $754.4 \mathrm{~mm} \mathrm{Hg}$ was employed for calculations. Oxygen concentration was calculated as follows: Ln $\left[\mathrm{O}_{2}\right]=-\Delta \mathrm{H} / \mathrm{RT}+\mathrm{C}^{\prime},\left[\mathrm{O}_{2}\right]$ being the oxygen concentration at a given temperature, $\mathrm{T}$ the thermodynamic temperature, $\mathrm{R}$ the gas constant $(8.314 \mathrm{~J} / \mathrm{K} \times \mathrm{mol}), \Delta \mathrm{H}$ the heat of solution in $\mathrm{kJ} / \mathrm{mol}$, and C' a constant. An extrapolation was used for calculating the oxygen concentration at different temperatures, as in the following example: the HTK oxygen solubility at $5^{\circ} \mathrm{C}$ and $760 \mathrm{~mm} \mathrm{Hg}$ of barometric pressure was $370 \mu \mathrm{M} \mathrm{O}_{2}$, which, as expected, is lower than the oxygen solubility in fresh water in the same conditions $(397 \mu \mathrm{M}$ $\mathrm{O}_{2}$ ). Values are presented as the mean \pm standard deviation of five measurements. HMP, hypothermic machine perfusion; HTK, histidine-tryptophan-ketoglutarate.
CS [147], and Viaspan ${ }^{\circledR}$ (UW solution) [4, 79], we determined different physicochemical parameters: COP ( $\mathrm{mm}$ $\mathrm{Hg})$, osmolality $\left(\mathrm{mOsm} / \mathrm{kg} \mathrm{H}_{2} \mathrm{O}\right)$, and viscosity $(\mathrm{cP})$ of the solutions (Table 1). Solution compositions are shown in Table 3.

Using the theoretical calculations expressed above, it is possible to determine the appropriate PEG or HES concentration which produces a suitable COP for hypothermic protocols.

Although hypothermic perfusion protocols are designed to recreate a physiological environment, this model is quite far from the normal physiology of an organ. For example, hypothermic perfusion differs from physiological perfusion in the following points: (1) The perfusion pressure is only $25 \%$ of the normal pressure (40 vs. $180 \mathrm{~mm} \mathrm{H}_{2} \mathrm{O}$ ) [148]. (2) The procedure of hypothermic perfusion is maintained at a temperature of $5{ }^{\circ} \mathrm{C}$. (3) At that temperature, the consumption of $\mathrm{O}_{2}$ by the tissue is approximately $5 \%$ of the physiological requirement at $37^{\circ} \mathrm{C}$ [149]. Point 3 involves a controversy not yet resolved, namely the appropriate oxygen concentration in an $\mathrm{H} / \mathrm{M} / \mathrm{S}$ perfusion solution. It will be necessary to establish the oxygen consumption by the organ with the perfusion protocol used to assure the correct gas concentration at the flow and pressure utilized. This research involves (1) the oxygen solubility in the perfusion solution at the perfusion temperature and (2) the organ oxygen consumption at the perfusion temperature.

Solubility curves of $\mathrm{O}_{2}$ at different temperatures in BGP-HMP (Fig. 3A) and HTK (Fig. 3B) solutions were experimentally determined as previously reported [150].

In previous experiments, a lower oxygen consumption from hypothermically perfused rat livers was reported [149]. The $\mathrm{O}_{2}$ consumption of isolated rat livers perfused at 5 and $10^{\circ} \mathrm{C}$ with BGP-HMP or HTK solutions saturated with air was also established [151]. It is necessary to provide appropriate oxygenation of the preservation solution during HMP perfusion protocols as a requirement for effective preservation and maintenance of organ viability and function.

\section{Experimental Observations about the Viscosity of the Perfusion Solutions at Low Temperatures}

Viscosity is a measure of the resistance of flow due to internal friction of a fluid. Owing to viscosity, it is necessary to apply a force when one layer of fluid is caused to move in relationship to another layer.

When the internal flow resistance is independent of the external force, as is the case with water, the fluid is called a Newtonian fluid. In the case of non-Newtonian fluids, they change viscosity when exposed to different 
Table 3. Preservation solution composition

\begin{tabular}{|c|c|c|c|c|c|}
\hline Preservation solution & UW [79] & $\begin{array}{l}\text { HTK-TiProtec } \\
\text { [79] }\end{array}$ & $\begin{array}{l}\text { BGP-HMP } \\
{[162]}\end{array}$ & BGP-CS & BG-basic \\
\hline Transplantation era & $\begin{array}{l}\text { 1990s to } \\
\text { current }\end{array}$ & $\begin{array}{l}\text { future - } \\
\text { in evaluation }\end{array}$ & $\begin{array}{l}\text { future - } \\
\text { in evaluation }\end{array}$ & $\begin{array}{l}\text { future - } \\
\text { in evaluation }\end{array}$ & $\begin{array}{l}\text { future - } \\
\text { in evaluation }\end{array}$ \\
\hline \multicolumn{6}{|l|}{ Electrolytes } \\
\hline \multicolumn{6}{|l|}{ Cations, $\mathrm{mm}$} \\
\hline $\mathrm{Na}^{+}$ & 30 & 16 & 100 & 100 & 100 \\
\hline $\mathrm{K}^{+}$ & 125 & 93 & 7 & 7 & 7 \\
\hline $\mathrm{Mg}^{++}$ & 5 & 6 & 5 & 5 & 5 \\
\hline $\mathrm{Ca}^{++}$ & & 0.05 & & & \\
\hline \multicolumn{6}{|l|}{ Anions, mM } \\
\hline $\mathrm{Cl}^{-}$ & & 103 & & & \\
\hline \multicolumn{6}{|l|}{$\mathrm{HCO}_{3}^{-}$} \\
\hline $\mathrm{PO}_{4}^{-*}$ & 25 & & 2.5 & 2.5 & 2.5 \\
\hline $\mathrm{SO}_{4}^{-}$ & 5 & & 5 & 5 & 5 \\
\hline Lactobionate** & 100 & & & & \\
\hline \multicolumn{6}{|l|}{ Buffers, $m M$} \\
\hline Histidine & & 198 & & & \\
\hline Glycine & & 5 & 15 & 15 & 15 \\
\hline Tryptophan & & 2 & & & \\
\hline BES & & & 30 & 30 & 30 \\
\hline \multicolumn{6}{|l|}{ Impermeants, $m M$} \\
\hline Glucose & & 10 & & & \\
\hline Raffinose & 30 & & & & \\
\hline Sucrose & & 37 & 20 & 20 & 20 \\
\hline \multicolumn{6}{|l|}{ Colloids } \\
\hline $\mathrm{HES}, \mathrm{g} / \mathrm{L}$ & 50 & & & & $\#$ \\
\hline PEG 35000, g/L & & & 1 & 11 & \#\# \\
\hline Osmolality & 320 & 305 & 290 & 303 & 290 \\
\hline $\mathrm{pH}$ & 7.4 & 7.0 & 7.4 & 7.4 & 7.4 \\
\hline \multicolumn{6}{|l|}{ Pharmacological agents, $\mathrm{mm}$} \\
\hline Adenosine & 5 & & 5 & 5 & 5 \\
\hline Glutathione & 3 & & 3 & 3 & 3 \\
\hline $\mathrm{N}$-acetyl histidine ${ }^{* * *}$ & & 30 & & & \\
\hline Allopurinol & 1 & & & & \\
\hline Alpha-ketoglutarate & & 2 & & & \\
\hline Aspartate & & 8 & & & \\
\hline Deferoxamine/L20 iron chelator & & $0.5 / 0.02$ & & & \\
\hline $\begin{array}{l}\text { HES, hydroxyethyl starch; } \mathrm{H}^{\prime} \\
\text { versity of Wisconsin. }{ }^{*} \mathrm{PO}_{4}^{-} \text {is both } \\
{ }^{* * *} \mathrm{~N} \text {-acetyl histidine is an osmoly } \\
\text { see Figure } 4 \mathrm{~A} \text {. }\end{array}$ & $\begin{array}{l}\text { TK, histidi } \\
\text { anion and } \\
\text { te and intr }\end{array}$ & $\begin{array}{l}\text { ne-tryptophan-ke } \\
\text { buffer. }{ }^{* *} \text { Lactobi } \\
\text { cellular buffer. }{ }^{\#} \mathrm{~F}\end{array}$ & $\begin{array}{l}\text { oglutarate; PEC } \\
\text { nate is an anion } \\
\text { or composition, }\end{array}$ & $\begin{array}{l}\text { polyethylene g } \\
\text { ith calcium che } \\
\text { ee Figure } 4 \mathrm{~B} .{ }^{\# \#}\end{array}$ & $\begin{array}{l}\text { lycol; UW, Uni- } \\
\text { ation properties. } \\
\text { for composition, }\end{array}$ \\
\hline
\end{tabular}

shearing stress, and the viscosities of such fluids are called apparent viscosities.

Temperature strongly influences the fluid's viscosity. The viscosity of blood at $4{ }^{\circ} \mathrm{C}$ is double that at $37^{\circ} \mathrm{C}$ [152]. In the liver, vascular resistance correlated well with the viscosity of the perfused fluid. In addition, the concentration of the oncotic agent contained in the preservation solution strongly affects its viscosity. It was shown that in static preservation procedures, the viscosity of the initial flushing solution may play an important role in determining the outcome of organ procurement from non- heart-beating donors [153]. It was reported that HES in UW preservation solution affects the organ washout due to red blood cell aggregation [152]. Livers flushed with solutions of low viscosity showed lower vascular resistance than those flushed with cold UW solution, and this improved the viability of the organ.

When considering preservation perfusion procedures such as H/S perfusion, the effects of temperature on fluid viscosity have not been rigorously investigated. For these reasons, it is important to study the results of this combination of effects on solution viscosity and how this affects 
organ outcome after preservation. To achieve this, the experimental results of different temperatures on viscosity of BG-basic preservation solution at different PEG concentrations are needed.
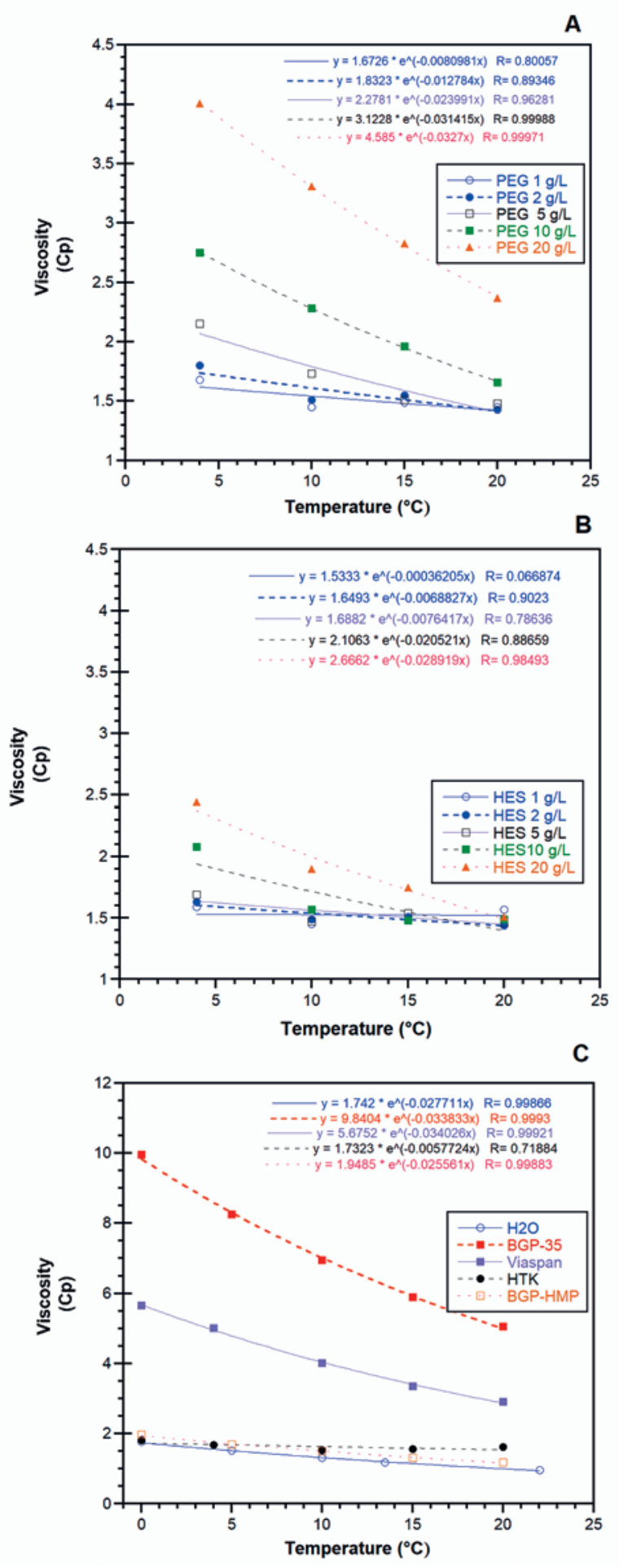

The BG-basic solution has the same chemical composition as BGP-HMP solution without oncotic agents (Fig. 4). We also determined the effect of adding HES to the BG-basic solution at different temperatures. Experimental results were obtained with a rotational digital viscosimeter (LCD Shanghai Nirun Intelligent Technology, model SNB-2).

The BGP-HMP solution was developed for hypothermic perfusion [145] and also tested for static preservation [147], the oncotic agent used was PEG 35000 at a concentration of $1 \mathrm{~g} / \mathrm{L}$. Figure 4 shows the effect of temperature on BG-basic solution viscosity at different PEG concentrations. A decrease in temperature exponentially increases the viscosity of the solution; this effect is magnified by the raise in PEG concentration. Interestingly, the substitution of PEG by HES increases the viscosity of the preservation solution with a temperature reduction, but this increase in concentration does not affect the viscosity in the same way as PEG. Finally, we compared similar concentrations of both compounds (PEG and HES) at low temperatures; PEG 35000 viscosity was significantly higher than HES viscosity. Figure 4 shows the comparison of the effect of temperature on the viscosity of the preservation solutions UW, HTK, BGP-HMP, BGP 35, and water.

In cold storage preservation, the role of the preservation solution viscosity becomes essential during organ washout to enable its distribution through the vasculature of the entire organ, preventing the effects of cold ischemia. However, in H/S perfusion techniques, where long perfusion times and good performances of the organ vasculature are required, the viscosity of the perfusion solution is associated with the concentration of the oncotic agent in a delicate balance between the control of interstitial edema and the perfusion flow and vascular resistance.

Fig. 4. Effect of temperature on the viscosity of preservation solutions. A Viscosity of BG-basic solution at different PEG concentrations. B Viscosity of BG-basic solution at different HES concentrations. C Effect of temperature on the viscosity of preservation solutions with respect to fresh water. Viaspan ${ }^{\circledR}$ (UW solution), HTK (Bretschneider solution), BGP-HMP (BES-gluconate-PEG for HMP solution), BGP-35 (Bes-gluconate-PEG [40 g/L] for liver microorgan cold storage solution [161]). All data obtained were fitted by an exponential equation showing a good regression coefficient (equations are displayed in the graph). The curves clearly show the increase in viscosity due to the reduction of temperature in all studied solutions. HES, hydroxyethyl starch; HMP, hypothermic machine perfusion; HTK, histidine-tryptophan-ketoglutarate; PEG, polyethylene glycol; UW, University of Wisconsin. 


\section{Analyzing Perfusion Parameters in the Preservation of Organs}

New technologies that are being developed in organ perfusion, which involve new roller pumps, new blood gas exchange devices, new centrifugal heads, miniaturized devices, and of course the development of the perfusion training programs mainly during the past 20 years, have led to the scientific evolution of perfusionists and to the development of these techniques. Ultimately, these new technologies are trying to create an appropriate environment to preserve the organ in the best possible way, outside of its usual environment, and maintain this situation until the organ is implanted. However, many debates still remain, dealing with the ways of achieving the optimal perfusion, but mainly with the relationship between perfusion pressures and the optimal preservation solution flow during extracorporeal circulation [154]. For instance, roller pumps by their design produce a pulsatile wave pattern of flow, which by producing the appropriate pulsatile wave could serve to overcome the opening pressure for the capillary bed, sufficient to allow brief but ongoing "bursts" of perfusion, whilst avoiding continuous exposure to this higher pressure, which is recognized as a contributing factor to develop a deleterious tissue edema [140].

Improvements in OPS continue to be made with new pharmacological approaches. New solutions have been developed for dynamic perfusion preservation and are now in clinical protocols [79]. The basis of this hypothermic protection is that cooling can help combat the deleterious effects of ischemia, but the consequences of cooling are not exclusively beneficial. Hypothermic storage is a compromise between the benefits and detriments of cooling [155]. Preservation advances allow the use of perfusion circuits to mimic healthy physiological conditions, which was originally presented by Downes et al. in 1973 [156]. This was based on the hypothesis that organs are best preserved in a condition as physiological as possible, by providing oxygen together with sufficient nutrients to support a constant metabolism. Initially, this preservation was conducted at body temperature. Only later was the development of hypothermia and SCS introduced, where the organ was cooled in vivo through a flushout with a cold preservation solution and subsequently stored on ice [157]. Inside this paper, Vekemans et al. compiled an interesting list of references related to pressure, flows, species, and temperature during hypothermic perfusion or normothermic machine perfusion. These actions permit the organ to recover from cellular stress and tissue injury during donor death and organ procurement, which can contribute to organ injury and rejection following transplantation, and also enable therapeutic intervention before transplantation. The advent of ex vivo organ per- fusion shows promise to make larger pools of donor organs available by enabling rehabilitation of organs that would otherwise be unsuitable for transplantation [158].

The other potential risk for organs exposed to continuous oxygenation at low temperatures during hypothermic perfusion is production of oxygen-derived free radicals with consequent cell damage, either because abnormally high oxygen tensions may be used by deliberate oxygenation of the perfusate, or because the normal antioxidant defenses, depending on consumption and regeneration of antioxidants, are disrupted at low temperatures [140].

\section{Warm Perfusion}

If one accepts the overall premise that perfusion of organs is a valuable approach to maintaining function, the obvious question is: why use low temperatures? Why not perfuse at normal body temperatures and avoid the metabolic challenge of cooling?

From the preceding sections, it will have become apparent that normothermic conditions were applied early in the history of in vitro organ perfusion, but the challenges of providing good oxygen carrying (using blood or blood components) without encountering problems of thrombus formation, vascular damage, and infection were insurmountable with the technology available at the time. A major concern when applying warm perfusion has been to supply not only sufficient oxygen-carrying capacity to support aerobic metabolism, but in addition all the other physiological mediators (the various substrates and cofactors) which are required for regulated homeostasis in the isolated organ. In some ways this can be considered analogous to the complex media developed for cell culture in vitro. Viewed from a different perspective, no advantage would be achieved from using a warm perfusion system, which induced early signaling markers for stress or inflammatory processes. The various components of normal blood provide the ideal perfusate for warm perfusion, but require sophisticated technology to maintain oxygenation and adequate intravascular flow, without inducing activation of circulating blood cells, microthrombi, and associated negative effects on organ microcirculation (a situation in some ways analogous to cardiopulmonary bypass). To replace blood with a cell-free synthetic solution poses different but equally difficult questions about reproducing the complete range of blood functions [140].

\section{Summary and Future Horizons}

Almost a decade has passed since our UNESCO Chair grouping reviewed how organ preservation was then being practiced and what research areas were potentially 
signposting new possibilities for clinical translation [80]. Organ perfusion was just re-establishing itself as a valuable clinical option for ex vivo preservation, after many years in which it had not been considered mainstream. Now, dynamic intervention by continuous perfusion is one of the most-discussed topics at transplantation meetings, with different systems and ranges of temperatures being applied in trials in all the major organ classes. These in turn are raising exciting possibilities for organ conditioning or repair as novel therapies during the perfusion period, which may well become a "hot topic" for research over the next 10 years. The concept of true long-term organ preservation at deep sub-zero temperatures also seemed to be at an impasse in previous times [80], whereas now there are small signs of renewed interest and investigation $[129,159,160]$, although these currently remain far from clinical application. In turn, they will depend on new kinds of dynamic perfusion. Perhaps these will be accelerated towards translation by new ideas and better understanding of the underpinning scientific principles by studies in cryobiology. Whichever technologies become predominant, the times ahead will certainly be very interesting in the quest to develop better organ preservation strategies and understand the cell and molecular changes in organs outside the body, which form the "supply line" for clinical transplantation.

\section{Acknowledgments}

The authors would like to acknowledge the importance of the UNESCO Chair in Cryobiology in the formulation of this review for providing the international contacts and stimulating collaborative research between our groups in different parts of the world. Part of this work was supported by the Italian Liver Foundation via a grant of the International Relationship Program of Regione FVG, Italy. A. Petrenko and A. Somov acknowledge the support of the Institute for Problems of Cryobiology and Cryomedicine, Kharkov, Ukraine, and Kharkov State University. The authors are also grateful for the Hepatobiliary Surgery Fellowship research funding by the Wellington HCA Hospital (London) for F. Froghi.

\section{Disclosure Statement}

The authors have no conflicts of interest to declare.

\section{References}

1 Sayegh MH, Carpenter CB. Transplantation 50 years later - progress, challenges, and promises. N Engl J Med. 2004 Dec;351(26): 2761-6.

2 Watson CJ, Dark JH. Organ transplantation: historical perspective and current practice. $\mathrm{Br}$ J Anaesth. 2012 Jan;108 Suppl 1:i29-42.

3 Marino IR, Cirillo C. An abridged photographic history of organ transplantation. Exp Clin Transplant. 2014 Mar;12 Suppl 1:11-6.

4 Belzer FO, Southard JH. Principles of solidorgan preservation by cold storage. Transplantation. 1988 Apr;45(4):673-6.

5 Fuller B, Guibert E, Rodríguez J. Lessons from Natural Cold-Induced Dormancy to Organ Preservation in Medicine and Biotechnology: From the "Backwoods to the Bedside." In: Lubzens E, Cerda J, Clark M, editors. Dormancy and Resistance in Harsh Environments. Berlin, Heidelberg: Springer Berlin Heidelberg; 2010. p. 253-78.

6 Brodie TG. The perfusion of surviving organs. J Physiol. 1903 Apr;29(3):266-75.

7 Locke FS, Rosenheim O. Contributions to the physiology of the isolated heart: the consumption of dextrose by mammalian cardiac muscle. J Physiol. 1907 Dec;36(4-5):205-20.

8 Carrel A, Lindbergh CA. The culture of organs. Science. 1935 Jun;81(2112):621-3.

9 Bickford RG, Winton FR. The influence of temperature on the isolated kidney of the dog. J Physiol. 1937 Mar;89(2):198-219.
10 Calne RY, Pegg DE, Pryse-Davies J, Brown FL. Renal preservation by ice-cooling: an experimental study relating to kidney transplantation from cadavers. Br Med J. 1963 Sep; 2(5358):651-5.

11 Pegg DE. An approach to hypothermic renal preservation. Cryobiology. 1978 Feb;15(1): $1-17$.

12 Collins GM, Bravo-Shugarman M, Terasaki PI. Kidney preservation for transportation. Initial perfusion and 30 hours' ice storage. Lancet. 1969 Dec;2(7632):1219-22.

13 Humphries AL Jr, Russell R, Stoddard LD, Moretz WH. Successful five-day kidney preservation. Perfusion with hypothermic, diluted plasma. Invest Urol. 1968 May;5(6):60918.

14 Humphries AL Jr, Russell R, Gregory J, Carter $\mathrm{RH}$, Moretz WH. Hypothermic perfusion of the canine kidney for 48 hours followed by reimplantation. Am Surg. 1964 Nov;30:74852.

15 Hobbs KE, Hunt AC, Palmer DB, Badrick FE, Morris AM, Mitra SK, et al. Hypothermic low flow liver perfusion as a means of porcine hepatic storage for six hours. Br J Surg. 1968 Sep; 55(9):696-703.

16 Starzl TE, Hakala TR, Shaw BW Jr, Hardesty RL, Rosenthal TJ, Griffith BP, et al. A flexible procedure for multiple cadaveric organ procurement. Surg Gynecol Obstet. 1984 Mar; 158(3):223-30.
17 Ross H, Marshall VC, Escott ML. 72-hr canine kidney preservation without continuous perfusion. Transplantation. 1976 Jun;21(6): 498-501.

18 Belzer FO, Glass NR, Sollinger HW, Hoffmann RM, Southard JH. A new perfusate for kidney preservation. Transplantation. 1982 Mar;33(3):322-3.

19 Cameron AM, Barandiaran Cornejo JF. Organ preservation review: history of organ preservation. Curr Opin Organ Transplant. 2015 Apr;20(2):146-51.

20 Zimmerman MA, Martin A, Hong JC. Basic considerations in organ perfusion physiology. Curr Opin Organ Transplant. 2016 Jun;21(3): 288-93.

21 Ferng AS, Schipper D, Connell AM, Marsh KM, Knapp S, Khalpey Z. Novel vs clinical organ preservation solutions: improved cardiac mitochondrial protection. J Cardiothorac Surg. 2017 Jan;12(1):7.

22 van Golen RF, Reiniers MJ, Olthof PB, van Gulik TM, Heger M. Sterile inflammation in hepatic ischemia/reperfusion injury: present concepts and potential therapeutics. J Gastroenterol Hepatol. 2013 Mar;28(3):394-400.

23 Land WG. The role of postischemic reperfusion injury and other nonantigen-dependent inflammatory pathways in transplantation. Transplantation. 2005 Mar;79(5):505-14. 
24 Olanders K, Sun Z, Börjesson A, Dib M, Andersson E, Lasson A, et al. The effect of intestinal ischemia and reperfusion injury on ICAM-1 expression, endothelial barrier function, neutrophil tissue influx, and protease inhibitor levels in rats. Shock. 2002 Jul;18(1): 86-92.

25 Post S, Palma P, Rentsch M, Gonzalez AP, Menger MD. Differential impact of Carolina rinse and University of Wisconsin solutions on microcirculation, leukocyte adhesion, Kupffer cell activity and biliary excretion after liver transplantation. Hepatology. 1993 Dec; 18(6):1490-7

26 Vollmar B, Glasz J, Post S, Menger MD. Role of microcirculatory derangements in manifestation of portal triad cross-clamping-induced hepatic reperfusion injury. J Surg Res. 1996 Jan;60(1):49-54.

27 Biberthaler P, Luchting B, Massberg S, Teupser D, Langer S, Leiderer $\mathrm{R}$, et al. Ischemia at 4 degrees $\mathrm{C}$ : a novel mouse model to investigate the effect of hypothermia on postischemic hepatic microcirculatory injury. Res Exp Med (Berl). 2001 Jan;200(2):93-105.

28 Schauer RJ, Bilzer M, Kalmuk S, Gerbes AL, Leiderer R, Schildberg FW, et al. Microcirculatory failure after rat liver transplantation is related to Kupffer cell-derived oxidant stress but not involved in early graft dysfunction. Transplantation. 2001 Nov;72(10):1692-9.

29 Durand MJ, Gutterman DD. Diversity in mechanisms of endothelium-dependent vasodilation in health and disease. Microcirculation. 2013 Apr;20(3):239-47.

30 Nanobashvili J, Neumayer C, Fuegl A, Blumer R, Prager M, Sporn E, et al. Development of "no-reflow" phenomenon in ischemia/reperfusion injury: failure of active vasomotility and not simply passive vasoconstriction. Eur Surg Res. 2003 Sep-Oct;35(5):417-24.

31 Olschewski P, Hunold G, Eipel C, Neumann U, Schöning W, Schmitz V, et al. Improved microcirculation by low-viscosity histidinetryptophan-ketoglutarate graft flush and subsequent cold storage in University of Wisconsin solution: results of an orthotopic rat liver transplantation model. Transpl Int. $2008 \mathrm{Dec}$; 21(12):1175-80.

32 Gao WS, Takei Y, Marzi I, Lindert KA, Caldwell-Kenkel JC, Currin RT, et al. Carolina rinse solution - a new strategy to increase survival time after orthotopic liver transplantation in the rat. Transplantation. 1991 Sep; 52(3):417-24.

33 Ballermann BJ, Dardik A, Eng E, Liu A. Shear stress and the endothelium. Kidney Int Suppl. 1998 Sep;67:S100-8.

34 Steinbauer M, Harris A, Hoffmann T, Messmer K. Pharmacological effects of dextrans on the postischemic leukocyte-endothelial interaction. Basel: Karger; 1996. p. 114-25.

35 Corso CO, Okamoto S, Leiderer R, Messmer $\mathrm{K}$. Resuscitation with hypertonic saline dextran reduces endothelial cell swelling and improves hepatic microvascular perfusion and function after hemorrhagic shock. J Surg Res. 1998 Dec;80(2):210-20.
36 Kawada N, Tran-Thi TA, Klein H, Decker K. The contraction of hepatic stellate (Ito) cells stimulated with vasoactive substances. Possible involvement of endothelin 1 and nitric oxide in the regulation of the sinusoidal tonus. Eur J Biochem. 1993 Apr;213(2):815-23.

37 Bełtowski J, Jamroz-Wiśniewska A. Hydrogen sulfide and endothelium-dependent vasorelaxation. Molecules. 2014 Dec;19(12): 21183-99.

38 Jarnagin WR, Rockey DC, Koteliansky VE, Wang SS, Bissell DM. Expression of variant fibronectins in wound healing: cellular source and biological activity of the EIIIA segment in rat hepatic fibrogenesis. J Cell Biol. 1994 Dec; 127(6 6 Pt 2):2037-48.

39 Amersi F, Shen XD, Moore C, Melinek J, Busuttil RW, Kupiec-Weglinski JW, et al. Fibronectin- $\alpha 4 \beta 1$ integrin-mediated blockade protects genetically fat Zucker rat livers from ischemia/reperfusion injury. Am J Pathol. 2003 Apr;162(4):1229-39.

40 Osborn L, Vassallo C, Browning BG, Tizard R, Haskard DO, Benjamin CD, et al. Arrangement of domains, and amino acid residues required for binding of vascular cell adhesion molecule- 1 to its counter-receptor VLA-4 (alpha 4 beta 1). J Cell Biol. 1994 Feb;124(4): 601-8.

41 Wyllie S, Barshes NR, Gao FQ, Karpen SJ, Goss JA. Failure of P-selectin blockade alone to protect the liver from ischemia-reperfusion injury in the isolated blood-perfused rat liver. World J Gastroenterol. 2008 Nov; 14(44): 6808-16.

42 Wong J, Johnston B, Lee SS, Bullard DC, Smith CW, Beaudet AL, et al. A minimal role for selectins in the recruitment of leukocytes into the inflamed liver microvasculature. J Clin Invest. 1997 Jun;99(11):2782-90.

43 Jaeschke H, Hasegawa T. Role of neutrophils in acute inflammatory liver injury. Liver Int. 2006 Oct;26(8):912-9.

44 Trocha SD, Kevil CG, Mancini MC, Alexander JS. Organ preservation solutions increase endothelial permeability and promote loss of junctional proteins. Ann Surg. 1999 Jul; 230(1):105-13.

45 Wessel F, Winderlich M, Holm M, Frye M, Rivera-Galdos R, Vockel M, et al. Leukocyte extravasation and vascular permeability are each controlled in vivo by different tyrosine residues of VE-cadherin. Nat Immunol. 2014 Mar;15(3):223-30

46 Worku D, Laluf S, McGee J, Goswami M, VanMeter K, Slakey DP. P-selectin expression in cold preserved kidneys in University of Wisconsin and histidine-tryptophan-ketoglutarate solutions. J Surg Res. 2011 Jul; 169(1):125-31.

47 Land WG. The Role of Damage-Associated Molecular Patterns (DAMPs) in Human Diseases: Part II: DAMPs as diagnostics, prognostics and therapeutics in clinical medicine. Sultan Qaboos Univ Med J. 2015 May; 15(2):e157-70

48 Shen XD, Ke B, Zhai Y, Gao F, Tsuchihashi S, Lassman CR, et al. Absence of toll-like receptor 4 (TLR4) signaling in the donor organ reduces ischemia and reperfusion injury in a murine liver transplantation model. Liver Transpl. 2007 Oct;13(10):1435-43.
49 Wu HS, Zhang JX, Wang L, Tian Y, Wang H, Rotstein O. Toll-like receptor 4 involvement in hepatic ischemia/reperfusion injury in mice. Hepatobiliary Pancreat Dis Int. 2004 May;3(2):250-3.

50 Su S, Wu J, Gong T, He K, Feng C, Zhang M, et al. Inhibition of High Mobility Group Box 1-Toll-Like Receptor-4 Signaling by Glycyrrhizin Contributes to the Attenuation of Cold Ischemic Injury of Liver in a Rat Model. Transplant Proc. 2016 Jan-Feb;48(1):191-8.

51 Schaer CA, Schoedon G, Imhof A, Kurrer MO, Schaer DJ. Constitutive endocytosis of CD163 mediates hemoglobin-heme uptake and determines the noninflammatory and protective transcriptional response of macrophages to hemoglobin. Circ Res. 2006 Oct; 99(9):943-50.

52 Kristiansen M, Graversen JH, Jacobsen C, Sonne O, Hoffman HJ, Law SK, et al. Identification of the haemoglobin scavenger receptor. Nature. 2001 Jan;409(6817):198-201.

53 Ozaki KS, Kimura S, Murase N. Use of carbon monoxide in minimizing ischemia/reperfusion injury in transplantation. Transplant Rev (Orlando). 2012 Apr;26(2):125-39.

54 Gregory SH, Wing EJ. Neutrophil-Kupffer cell interaction: a critical component of host defenses to systemic bacterial infections. J Leukoc Biol. 2002 Aug;72(2):239-48.

55 Linehan SA, Martínez-Pomares L, Gordon S. Macrophage lectins in host defence. Microbes Infect. 2000 Mar;2(3):279-88.

56 Sindram D, Porte RJ, Hoffman MR, Bentley RC, Clavien PA. Platelets induce sinusoidal endothelial cell apoptosis upon reperfusion of the cold ischemic rat liver. Gastroenterology. 2000 Jan;118(1):183-91.

57 Carestia A, Kaufman T, Schattner M. Platelets: New Bricks in the Building of Neutrophil Extracellular Traps. Front Immunol. 2016 Jul; $7: 271$.

58 Morrell CN, Sun H, Swaim AM, Baldwin WM 3rd. Platelets an inflammatory force in transplantation. Am J Transplant. 2007 Nov;7(11): 2447-54.

59 Vogel S, Bodenstein R, Chen Q, Feil S, Feil R, Rheinlaender J, et al. Platelet-derived HMGB1 is a critical mediator of thrombosis. J Clin Invest. 2015 Dec;125(12):4638-54.

60 Myronovych A, Murata S, Chiba M, Matsuo $\mathrm{R}$, Ikeda $\mathrm{O}$, Watanabe $\mathrm{M}$, et al. Role of platelets on liver regeneration after $90 \%$ hepatectomy in mice. J Hepatol. 2008 Sep;49(3):36372.

61 Kurokawa T, Ohkohchi N. Platelets in liver disease, cancer and regeneration. World J Gastroenterol. 2017 May;23(18):3228-39.

62 Nieswandt B, Pleines I, Bender M. Platelet adhesion and activation mechanisms in arterial thrombosis and ischaemic stroke. J Thromb Haemost. 2011 Jul;9 Suppl 1:92-104.

63 Förstermann U, Li H. Therapeutic effect of enhancing endothelial nitric oxide synthase (eNOS) expression and preventing eNOS uncoupling. Br J Pharmacol. 2011 Sep;164(2): 213-23.

64 Schött U, Solomon C, Fries D, Bentzer P. The endothelial glycocalyx and its disruption, protection and regeneration: a narrative review. Scand J Trauma Resusc Emerg Med. 2016 Apr;24(1):48.
Organ Preservation into the 2020s:

The Era of Dynamic Intervention 
65 van Golen RF, Reiniers MJ, Vrisekoop N, Zuurbier CJ, Olthof PB, van Rheenen J, et al. The mechanisms and physiological relevance of glycocalyx degradation in hepatic ische$\mathrm{mia} /$ reperfusion injury. Antioxid Redox Signal. 2014 Sep;21(7):1098-118.

66 Woodcock TE, Woodcock TM. Revised Starling equation and the glycocalyx model of transvascular fluid exchange: an improved paradigm for prescribing intravenous fluid therapy. Br J Anaesth. 2012 Mar;108(3):38494.

67 Becker BF, Jacob M, Leipert S, Salmon AH, Chappell D. Degradation of the endothelial glycocalyx in clinical settings: searching for the sheddases. Br J Clin Pharmacol. 2015 Sep; 80(3):389-402.

68 Beijert I, Mert S, Huang V, Karimian N, Geerts S, Hafiz EO, et al. Endothelial Dysfunction in Steatotic Human Donor Livers: A Pilot Study of the Underlying Mechanism During Subnormothermic Machine Perfusion. Transplant Direct. 2018 Apr;4(5):e345.

69 Lopez A, Panisello-Rosello A, Castro-Benitez C, Adam R. Glycocalyx preservation and NO production in fatty livers - the protective role of high molecular polyethylene glycol in cold ischemia injury. Int J Mol Sci. 2018 Aug; 19(8):E2375.

70 Springer TA. Adhesion receptors of the immune system. Nature. 1990 Aug;346(6283): 425-34.

71 Chappell D, Brettner F, Doerfler N, Jacob M, Rehm M, Bruegger D, et al. Protection of glycocalyx decreases platelet adhesion after ischaemia/reperfusion: an animal study. Eur J Anaesthesiol. 2014 Sep;31(9):474-81.

72 Chappell D, Dörfler N, Jacob M, Rehm M, Welsch U, Conzen P, et al. Glycocalyx protection reduces leukocyte adhesion after ischemia/reperfusion. Shock. 2010 Aug;34(2): 133-9.

73 McDonald KK, Cooper S, Danielzak L, Leask RL. Glycocalyx Degradation Induces a Proinflammatory Phenotype and Increased Leukocyte Adhesion in Cultured Endothelial Cells under Flow. PLoS One. 2016 Dec;11(12): e0167576.

74 Schmidt EP, Yang Y, Janssen WJ, Gandjeva A Perez MJ, Barthel L, et al. The pulmonary endothelial glycocalyx regulates neutrophil adhesion and lung injury during experimental sepsis. Nat Med. 2012 Aug;18(8):1217-23.

75 Termeer C, Benedix F, Sleeman J, Fieber C, Voith U, Ahrens T, et al. Oligosaccharides of Hyaluronan activate dendritic cells via tolllike receptor 4. J Exp Med. 2002 Jan;195(1): 99-111.

76 Schiefer J, Lebherz-Eichinger D, Erdoes G, Berlakovich G, Bacher A, Krenn CG, et al. Alterations of Endothelial Glycocalyx During Orthotopic Liver Transplantation in Patients With End-Stage Liver Disease. Transplantation. 2015 Oct;99(10):2118-23.

77 Murphy LS, Wickersham N, McNeil JB, Shaver CM, May AK, Bastarache JA, et al. Endothelial glycocalyx degradation is more severe in patients with non-pulmonary sepsis compared to pulmonary sepsis and associates with risk of ARDS and other organ dysfunction. Ann Intensive Care. 2017 Oct;7(1):102.
78 Johansson PI, Stensballe J, Rasmussen LS, Ostrowski SR. A high admission syndecan-1 level, a marker of endothelial glycocalyx degradation, is associated with inflammation, protein C depletion, fibrinolysis, and increased mortality in trauma patients. Ann Surg. 2011 Aug;254(2):194-200.

79 Fuller B, Froghi F, Davidson B. Organ preservation solutions: linking pharmacology to survival for the donor organ pathway. Curr Opin Organ Transplant. 2018 Jun;23(3):3618

80 Guibert EE, Petrenko AY, Balaban CL, Somov AY, Rodriguez JV, Fuller BJ. Organ preservation: current concepts and new strategies for the next decade. Transfus Med Hemother. 2011;38(2):125-42.

81 Ali F, Dua A, Cronin DC. Changing paradigms in organ preservation and resuscitation. Curr Opin Organ Transplant. 2015 Apr; 20(2):152-8.

82 Peglow S, Toledo AH, Anaya-Prado R, LopezNeblina F, Toledo-Pereyra LH. Allopurinol and xanthine oxidase inhibition in liver ischemia reperfusion. J Hepatobiliary Pancreat Sci. 2011 Mar; 18(2):137-46.

83 Gaucher C, Boudier A, Bonetti J, Clarot I, Leroy P, Parent M. Glutathione: Antioxidant Properties Dedicated to Nanotechnologies. Antioxidants. 2018 Apr;7(5):62.

84 Nayak BN, Buttar HS. Evaluation of the antioxidant properties of tryptophan and its metabolites in in vitro assay. J Complement Integr Med. 2016 Jun;13(2):129-36.

85 Liu JH, Chen MM, Huang JW, Wann H, Ho LK, Pan WH, et al. Therapeutic effects and mechanisms of action of mannitol during $\mathrm{H} 2 \mathrm{O} 2$-induced oxidative stress in human retinal pigment epithelium cells. J Ocul Pharmacol Ther. 2010 Jun;26(3):249-57.

86 Rauen U, de Groot H. New insights into the cellular and molecular mechanisms of cold storage injury. J Investig Med. 2004 Jul;52(5): 299-309.

87 Radovits T, Lin LN, Zotkina J, Koch A, Rauen U, Köhler G, et al. Endothelial dysfunction after long-term cold storage in HTK organ preservation solutions: effects of iron chelators and $\mathrm{N}$ - $\alpha$-acetyl-L-histidine. J Heart Lung Transplant. 2008 Feb;27(2):208-16.

88 Wille T, Gonder S, Thiermann H, Seeger T, Rauen U, Worek F. Evaluation of functional and structural alterations in muscle tissue after short-term cold storage in a new tissue preservation solution. Cells Tissues Organs. 2011;194(6):501-9.

89 Veres G, Hegedűs P, Barnucz E, Schmidt H, Radovits T, Zöller R, et al. TiProtec preserves endothelial function in a rat model. J Surg Res. 2016 Jan;200(1):346-55.

90 Pless-Petig G, Walter B, Bienholz A, Rauen U. Mitochondrial Impairment as a Key Factor for the Lack of Attachment after Cold Storage of Hepatocyte Suspensions. Cell Transplant. 2017 Dec;26(12):1855-67.

91 Plotnikov EY, Silachev DN, Jankauskas SS, Rokitskaya TI, Chupyrkina AA, Pevzner IB, et al. Mild uncoupling of respiration and phosphorylation as a mechanism providing nephro- and neuroprotective effects of penetrating cations of the SkQ family. Biochemistry (Mosc). 2012 Sep;77(9):1029-37.
92 Petrenko AY, Cherkashina DV, Somov AY, Tkacheva EN, Semenchenko OA, Lebedinsky AS, et al. Reversible mitochondrial uncoupling in the cold phase during liver preservation/reperfusion reduces oxidative injury in the rat model. Cryobiology. 2010 Jun;60(3):293-300.

93 Zhang ZW, Xu XC, Liu T, Yuan S. Mitochondrion-Permeable Antioxidants to Treat ROS-Burst-Mediated Acute Diseases. Oxid Med Cell Longev. 2016;2016:6859523.

94 Skulachev VP, Anisimov VN, Antonenko YN, Bakeeva LE, Chernyak BV, Erichev VP, et al. An attempt to prevent senescence: a mitochondrial approach. Biochim Biophys Acta. 2009 May;1787(5):437-61.

95 Apostolova N, Victor VM. Molecular strategies for targeting antioxidants to mitochondria: therapeutic implications. Antioxid Redox Signal. 2015 Mar;22(8):686-729.

96 Cherkashina DV, Sosimchik IA, Semenchenko OA, Volina VV, Petrenko AY. Mitochondria-targeted plastoquinone derivative $\operatorname{SkQ}(1)$ decreases ischemia-reperfusion injury during liver hypothermic storage for transplantation. Biochemistry (Mosc). 2011 Sep;76(9):1022-9.

97 Chen C, Hou J. Mesenchymal stem cellbased therapy in kidney transplantation. Stem Cell Res Ther. 2016 Feb;7(1):16.

98 Sun Q, Huang Z, Han F, Zhao M, Cao R, Zhao D, et al. Allogeneic mesenchymal stem cells as induction therapy are safe and feasible in renal allografts: pilot results of a multicenter randomized controlled trial. J Transl Med. 2018 Mar;16(1):52.

99 Torres Crigna A, Daniele C, Gamez C, Medina Balbuena S, Pastene DO, Nardozi D, et al. Stem/Stromal Cells for Treatment of Kidney Injuries With Focus on Preclinical Models. Front Med (Lausanne). 2018 Jun;5: 179.

100 Parekkadan B, van Poll D, Suganuma K, Carter EA, Berthiaume F, Tilles AW, et al. Mesenchymal stem cell-derived molecules reverse fulminant hepatic failure. PLoS One. 2007 Sep;2(9):e941.

101 Fu Y, Karbaat L, Wu L, Leijten J, Both SK, Karperien M. Trophic Effects of Mesenchymal Stem Cells in Tissue Regeneration. Tissue Eng Part B Rev. 2017 Dec;23(6):515-28.

102 La Francesca S, Ting AE, Sakamoto J, Rhudy J, Bonenfant NR, Borg ZD, et al. Multipotent adult progenitor cells decrease cold ischemic injury in ex vivo perfused human lungs: an initial pilot and feasibility study. Transplant Res. 2014 Nov;3(1):19.

103 Waller KR, Foley JD, McAnulty J, Murphy CJ. Trophic Factor Supplementation Protects Kidney Tubule Cells from Cold Ischemic Injury and Decreases Free Radical Production during Rewarming. Cell Preserv Technol. 2007;5(3):132-6.

104 Kwon YS, Foley JD, Russell P, McAnulty JF, Murphy CJ. Prevention of cold ischemia/ rewarming-induced ERK 1/2, p38 kinase and HO-1 activation by trophic factor supplementation of UW solution. Cryobiology. 2008 Aug;57(1):72-4. 
105 McAnulty JF, Reid TW, Waller KR, Murphy CJ. Successful six-day kidney preservation using trophic factor supplemented media and simple cold storage. Am J Transplant. 2002 Sep;2(8):712-8.

106 Ambiru S, Uryuhara K, Talpe S, Dehoux JP, Jacobbi L, Murphy CJ, et al. Improved survival of orthotopic liver allograft in swine by addition of trophic factors to University of Wisconsin solution. Transplantation. 2004 Jan;77(2):302-19.

107 Cherkashina DV, Petrenko AY. Hepatoprotective effect of fetal tissue cytosol and its thermostable fraction in rats with carbon tetrachloride-induced hepatitis. Bull Exp Biol Med. 2006 Apr;141(4):544-7.

108 Ochenashko OV, Nikitchenko YV, Volkova NA, Mazur SP, Somov AY, Fuller BJ, et al. Functional hepatic recovery after xenotransplantation of cryopreserved fetal liver cells or soluble cell-factor administration in a cirrhotic rat model: are viable cells necessary? J Gastroenterol Hepatol. 2008 Jul;23 (7 Pt 2):e275-82.

109 Cherkashina DV, Tkacheva EN, Somov AY, Semenchenko OA, Nardid OA, Petrenko AY. Capacity of bioregulators of stem and progenitor cells to strongly affect liver redox-dependent processes. Rejuvenation Res. 2011 Dec;14(6):661-7.

110 Cherkashina DV, Semenchenko OA, Grischuk VP, Fuller BJ, Petrenko AY. Supplementation with fetal-specific factors ameliorates oxidative liver damage during hypothermic storage and reperfusion in a rat model. Cell Preserv Technol. 2005;3(3): 201-10

111 Cherkashina DV, Sosimchyk IA, Semenchenko OA, Semenchenko AY, Volina VV, Petrenko AY. Bioregulators of stem and progenitor cells in preservation solution reduce cold ischemia-reperfusion injury of isolated rat livers. Biofactors. 2016 May; 42(3):287-95.

112 Zaouali MA, Padrissa-Altés S, Ben Mosbah I, Alfany-Fernandez I, Massip-Salcedo M, Casillas-Ramirez A, et al. Improved rat steatotic and nonsteatotic liver preservation by the addition of epidermal growth factor and insulin-like growth factor-I to University of Wisconsin solution. Liver Transpl. 2010 Sep;16(9):1098-111.

113 Karangwa SA, Dutkowski P, Fontes P, Friend PJ, Guarrera JV, Markmann JF, et al. Machine Perfusion of Donor Livers for Transplantation: A Proposal for Standardized Nomenclature and Reporting Guidelines. Am J Transplant. 2016 Oct;16(10): 2932-42.

114 Schlegel A, Muller X, Dutkowski P. Hypothermic liver perfusion. Curr Opin Organ Transplant. 2017 Dec;22(6):563-70.

115 Burlage LC, Karimian N, Westerkamp AC, Visser N, Matton AP, van Rijn R, et al. Oxygenated hypothermic machine perfusion after static cold storage improves endothelial function of extended criteria donor livers. HPB (Oxford). 2017 Jun;19(6):538-46.

116 Westerkamp AC, Karimian N, Matton AP, Mahboub P, van Rijn R, Wiersema-Buist J, et al. Oxygenated Hypothermic Machine Perfusion After Static Cold Storage Im- proves Hepatobiliary Function of Extended Criteria Donor Livers. Transplantation. 2016 Apr;100(4):825-35

117 Stegemann J, Minor T. Energy charge restoration, mitochondrial protection and reversal of preservation induced liver injury by hypothermic oxygenation prior to reperfusion. Cryobiology. 2009 Jun;58(3):331-6.

118 Minor T, von Horn C, Paul A. Role of temperature in reconditioning and evaluation of cold preserved kidney and liver grafts. Curr Opin Organ Transplant. 2017 Jun; 22(3):267-73.

119 Burra P, Zanetto A, Russo FP, Germani G. Organ Preservation in Liver Transplantation. Semin Liver Dis. 2018 Aug;38(3):260-9.

120 Guarrera JV, Henry SD, Samstein B, OdehRamadan R, Kinkhabwala M, Goldstein MJ, et al. Hypothermic machine preservation in human liver transplantation: the first clinical series. Am J Transplant. 2010 Feb;10(2): 372-81.

121 van Rijn R, Karimian N, Matton AP, Burlage LC, Westerkamp AC, van den Berg AP, et al. Dual hypothermic oxygenated machine perfusion in liver transplants donated after circulatory death. Br J Surg. 2017 Jun; 104(7):907-17.

122 Clavien PA, Dutkowski P. Advances in hypothermic perfusion. Liver Transpl. 2017 Oct;23(S1):S52-5.

123 Hessheimer AJ, Fondevila C. Liver perfusion devices: how close are we to widespread application? Curr Opin Organ Transplant. 2017 Apr;22(2):105-11.

124 Bruinsma BG, Yeh H, Özer S, Martins PN, Farmer A, Wu W, et al. Subnormothermic machine perfusion for ex vivo preservation and recovery of the human liver for transplantation. Am J Transplant. 2014 Jun; 14(6):1400-9.

125 Selten J, Schlegel A, de Jonge J, Dutkowski P. Hypo- and normothermic perfusion of the liver: which way to go? Best Pract Res Clin Gastroenterol. 2017 Apr;31(2):171-9.

126 Spetzler VN, Goldaracena N, Echiverri J, Kaths JM, Louis KS, Adeyi OA, et al. Subnormothermic ex vivo liver perfusion is a safe alternative to cold static storage for preserving standard criteria grafts. Liver Transpl. 2016 Jan;22(1):111-9.

127 Guarrera JV, Estevez J, Boykin J, Boyce R, Rashid J, Sun S, et al. Hypothermic machine perfusion of liver grafts for transplantation: technical development in human discard and miniature swine models. Transplant Proc. 2005 Jan-Feb;37(1):323-5.

128 Hoyer DP, Mathé Z, Gallinat A, Canbay AC, Treckmann JW, Rauen U, et al. Controlled Oxygenated Rewarming of Cold Stored Livers Prior to Transplantation: First Clinical Application of a New Concept. Transplantation. 2016 Jan;100(1):147-52.

129 Bruinsma BG, Uygun K. Subzero organ preservation: the dawn of a new ice age? Curr Opin Organ Transplant. 2017 Jun; 22(3):281-6.

130 Berendsen TA, Bruinsma BG, Puts CF, Saeidi N, Usta OB, Uygun BE, et al. Supercooling enables long-term transplantation survival following 4 days of liver preservation. Nat Med. 2014 Jul;20(7):790-3.
131 Fontes P, Lopez R, van der Plaats A, Vodovotz $Y$, Minervini $M$, Scott $V$, et al. Liver preservation with machine perfusion and a newly developed cell-free oxygen carrier solution under subnormothermic conditions. Am J Transplant. 2015 Feb;15(2): 381-94

132 Laing RW, Mergental H, Mirza DF. Normothermic ex-situ liver preservation: the new gold standard. Curr Opin Organ Transplant. 2017 Jun;22(3):274-80.

133 Liu Q, Berendsen T, Izamis ML, Uygun B, Yarmush ML, Uygun K. Perfusion defatting at subnormothermic temperatures in steatotic rat livers. Transplant Proc. 2013 Nov; 45(9):3209-13.

134 Ravikumar R, Jassem W, Mergental H, Heaton N, Mirza D, Perera MT, et al. Liver transplantation after ex vivo normothermic machine preservation: a phase 1 (first-inman) clinical trial. Am J Transplant. 2016 Jun;16(6):1779-87.

135 Liu Q, Nassar A, Buccini L, Grady P, Soliman B, Hassan A, et al. Ex situ 86-hour liver perfusion: pushing the boundary of organ preservation. Liver Transpl. 2018 Apr; 24(4):557-61.

136 Nasralla D, Coussios CC, Mergental H, Akhtar MZ, Butler AJ, Ceresa CD, et al.; Consortium for Organ Preservation in Europe. A randomized trial of normothermic preservation in liver transplantation. $\mathrm{Na}$ ture. 2018 May;557(7703):50-6.

137 Mergental H, Perera MT, Laing RW, Muiesan P, Isaac JR, Smith A, et al. Transplantation of Declined Liver Allografts Following Normothermic Ex-Situ Evaluation. Am J Transplant. 2016 Nov;16(11):323545.

138 Hosgood SA, Nicholson HF, Nicholson ML. Oxygenated kidney preservation techniques. Transplantation. 2012 Mar;93(5): 455-9.

139 Fuller BJ, Attenburrow VD. The effects of increasing the oncotic and osmotic pressure of the perfusate on bloodless hypothermic perfusion of liver in the rat. Cryobiology. 1978 Oct;15(5):545-50.

140 Fuller BJ, Lee CY. Hypothermic perfusion preservation: the future of organ preservation revisited? Cryobiology. 2007 Apr;54(2): 129-45.

141 Weisberg HF. Osmotic pressure of the serum proteins. Ann Clin Lab Sci. 1978 MarApr;8(2):155-64.

142 Skillman JJ, Parikh BM, Tanenbaum BJ. Pulmonary arteriovenous admixture. Improvement with albumin and diuresis. Am J Surg. 1970 Apr;119(4):440-7.

143 Skillman JJ. The role of albumin and oncotically active fluids in shock. Crit Care Med. 1976 Mar-Apr;4(2):55-61.

144 Soto-Rivera A. Relationship between protein osmotic pressure and density in plasma from cats, dogs, and humans. Proc Soc Exp Biol Med. 1949 Jun;71(2):184-6.

145 Carnevale ME, Balaban CL, Guibert EE Bottai H, Rodríguez JV. 56. Evaluation of a new solution for hypothermic machine perfusion (HMP) of the liver. II - A study in the perfused rat liver in vitro. Cryobiology. 2012;65(3):65. 
146 Starling EH. On the Absorption of Fluids from the Connective Tissue Spaces. J Physiol. 1896 May;19(4):312-26.

147 Carnevale ME, Lausada N, Juan de Paz L, Stringa P, Rumbo M, Guibert EE, et al. Comparison of the novel preservation solution BGP-HMP vs HTK solution for static cold storage (SCS) of rat livers. Liver Transplant. 2018 [submitted for publication].

148 't Hart NA, der van Plaats A, Leuvenink HG, van Goor H, Wiersema-Buist J, Verkerke GJ, et al. Determination of an adequate perfusion pressure for continuous dual vessel hypothermic machine perfusion of the rat liver. Transpl Int. 2007 Apr;20(4):343-52.

149 Rodriguez JV, Federico MB, Pizarro MD, Guibert EE, Quintana AB, Scandizzi AL. A device to measure oxygen consumption during the hypothermic perfusion of the liver. Cryo Letters. 2009 Sep-Oct;30(5):33546.

150 Llarrull MS, Pizarro MD, Scandizzi AL, Bottai H, Guibert EE, Rodriguez JV. Cold preservation of isolated hepatocytes in UW solution: experimental studies on the respiratory activity at 0 degrees C. Cryo Letters. 2007 Sep-Oct;28(5):313-28.

151 Pascucci F, Carnevale ME, Balaban CL, Mamprin ME, Guibert EE, Rodríguez JV. 55. Evaluation of a new solution for hypo- thermic machine perfusion (HMP) of the liver. I - Composition and physicochemical parameters. Cryobiology. 2012;65(3):357.

152 van der Plaats A, 't Hart NA, Morariu AM, Verkerke GJ, Leuvenink HG, Ploeg RJ, et al. Effect of University of Wisconsin organpreservation solution on haemorheology. Transpl Int. 2004 Jun;17(5):227-33.

153 Tojimbara T, Wicomb WN, Garcia-Kennedy R, Burns W, Hayashi M, Collins G, et al. Liver transplantation from non-heart beating donors in rats: influence of viscosity and temperature of initial flushing solutions on graft function. Liver Transpl Surg. 1997 Jan; 3(1):39-45.

154 Pappa MD, Theodosiadis NV, Paliouras D, Rallis T, Gogakos AS, Barbetakis N, et al. Advanced perfusion techniques - flow versus pressure. J Biomed (Syd). 2017;2:20-4.

155 Taylor MJ, Baicu SC. Current state of hypothermic machine perfusion preservation of organs: the clinical perspective. Cryobiology. 2010 Jul;60(3 Suppl):S20-35.

156 Downes G, Hoffman R, Huang J, Belzer FO. Mechanism of action of washout solutions for kidney preservation. Transplantation. 1973 Jul;16(1):46-53.

157 Vekemans K, Liu Q, Pirenne J, Monbaliu D. Artificial circulation of the liver: machine perfusion as a preservation method in liver transplantation. Anat Rec (Hoboken). 2008 Jun;291(6):735-40.

158 Giwa S, Lewis JK, Alvarez L, Langer R, Roth AE, Church GM, et al. The promise of organ and tissue preservation to transform medicine. Nat Biotechnol. 2017 Jun;35(6):53042.

159 Finger EB, Bischof JC. Cryopreservation by vitrification: a promising approach for transplant organ banking. Curr Opin Organ Transplant. 2018 Jun;23(3):353-60.

160 Bruinsma BG, Berendsen TA, Izamis ML, Yeh H, Yarmush ML, Uygun K. Supercooling preservation and transplantation of the rat liver. Nat Protoc. 2015 Mar;10(3):48494.

161 Mandolino C, Pizarro MD, Quintana AB, Rodríguez JV, Mamprin ME. Hypothermic preservation of rat liver microorgans (LMOs) in bes-gluconate solution. Protective effects of polyethyleneglycol (PEG) on total water content and functional viability. Ann Hepatol. 2011 Apr-Jun;10(2):196206.

162 Carnevale ME, Balaban CL, Guibert EE, Bottai H, Rodriguez JV. Hypothermic machine perfusion versus cold storage in the rescuing of livers from non-heart-beating donor rats. Artif Organs. 2013 Nov;37(11): 985-91. 